\title{
Minimizing errors in RT-PCR detection and quantification of SARS-CoV-2 RNA for Wastewater Surveillance
}

Warish Ahmed ${ }^{1, *}$, Stuart L. Simpson², Paul M. Bertsch ${ }^{1}$, Kyle Bibby ${ }^{3}$, Aaron Bivins ${ }^{3}$, Linda L. Blackall $^{4}$, Silvia Bofill-Mas ${ }^{5}$, Albert Bosch ${ }^{6}$, João Brandão7, Phil M. Choi,9, Mark Ciesielski ${ }^{10}$, Erica Donner ${ }^{11}$, Nishita D'Souza ${ }^{12}$, Andreas H. Farnleitner ${ }^{13,14}$, Daniel Gerrity ${ }^{15}$, Raul Gonzalez $^{16}$, John F. Griffith ${ }^{17}$, Pradip Gyawali ${ }^{18}$, Charles N. Haas ${ }^{19}$, Kerry A. Hamilton ${ }^{20}$, Chanditha Hapuarachchi ${ }^{21}$, Valerie J. Harwood ${ }^{22}$, Rehnuma Haque ${ }^{23}$, Greg Jackson ${ }^{8}$, Stuart J. Khan ${ }^{24}$, Wesaal Khan ${ }^{25}$, Masaaki Kitajima ${ }^{26}$, Asja Korajkic ${ }^{27}$, Giuseppina La Rosa ${ }^{28}$, Blythe A. Layton ${ }^{29}$, Erin Lipp ${ }^{30}$, Sandra McLellan ${ }^{31}$, Brian McMinn'27, Gertjan Medema ${ }^{32}$, Suzanne Metcalfe $^{1}$, Wim G. Meijer ${ }^{33}$, Jochen F. Mueller ${ }^{9}$, Heather Murphy ${ }^{34}$, Coleen C. Naughton ${ }^{35}$, Rachel T. Noble ${ }^{10}$, Sudhi Payyappat ${ }^{36}$, Susan Petterson ${ }^{37,38}$, Tarja Pitkänen ${ }^{39,40}$, Veronica B. Rajal ${ }^{41}$, Brandon Reyneke ${ }^{25}$, Fernando A. Roman Jr. ${ }^{35}$, Joan B. Rose ${ }^{12}$, Marta Rusiñol ${ }^{42}$, Michael Sadowsky ${ }^{43}$, Laura Sala-Comorera ${ }^{33}$, Yin Xiang Setoh ${ }^{21}$, Samendra Sherchan ${ }^{44}$, Kwanrawee Sirikanchana ${ }^{45}$, Wendy Smith ${ }^{1}$, Joshua Steele ${ }^{17}$, Rosalie Subburg ${ }^{46}$, Erin M. Symonds ${ }^{47}$, Phong Thai ${ }^{9}$, Kevin V. Thomas ${ }^{9}$, Josh Tynan ${ }^{9}$, Simon Toze ${ }^{1}$, Janelle Thompson ${ }^{48,49}$, Andy S. Whiteley ${ }^{50}$, Judith Chui Ching Wong ${ }^{21}$, Daisuke Sano ${ }^{51}$, Stefan Wuertz $^{49,52}$, Irene Xagoraraki ${ }^{53}$, Qian Zhang ${ }^{43}$, Amity G. Zimmer-Faust ${ }^{17}$, Orin C. Shanks ${ }^{27}$

${ }^{1}$ CSIRO Land and Water, Ecosciences Precinct, 41 Boggo Road, QLD 4102, Australia.

${ }^{2}$ CSIRO Land and Water, Lucas Heights, NSW 2234, Australia.

3Department of Civil \& Environmental Engineering \& Earth Science, University of Notre Dame, 156

Fitzpatrick Hall, Notre Dame, IN, 46556, USA.

${ }^{4}$ School of BioSciences, The University of Melbourne, Melbourne, VIC, Australia.

${ }^{5}$ Department of Genetics, Microbiology and Statistics, Faculty of Biology, University of Barcelona, Catalonia, Spain.

${ }^{6}$ Enteric Virus Laboratory, Dep. Genetics, Microbiology and Statistics, University of Barcelona, Avda. Diagonal 643, 08028 Barcelona, Spain.

${ }^{7}$ Department of Environmental Health, National Institute of Health Dr. Ricardo Jorge, Lisboa, Portugal. ${ }^{8}$ Water Unit, Health Protection Branch, Prevention Division, Queensland Health, QLD, Australia. ${ }^{9}$ The University of Queensland, Queensland Alliance for Environmental Health Sciences, QLD, Australia.

10University of North Carolina Institute of Marine Sciences, Morehead City, NC, United States of America.

${ }^{11}$ Future Industries Institute, University of South Australia, University Boulevard, Mawson Lakes, SA 5095, Australia.

${ }^{12}$ Department of Fisheries and Wildlife, Michigan State University, E. Lansing MI USA.

${ }^{13}$ Institute of Chemical, Environmental \& Bioscience Engineering, Research Group Environmental Microbiology and Molecular Diagnostic, 166/5/3, Technische Universität Wien, Vienna, Austria.

${ }^{14}$ Research Division Water Quality and Health, Department Pharmacology, Physiology and

Microbiology, Karl Landsteiner University of Health Sciences, Dr. Karl-Dorrek-Straße 30, 3500 Krems an der Doau, Austria.

${ }^{15}$ Southern Nevada Water Authority, P.O. Box 99954, Las Vegas, NV, 89193, USA.

${ }^{16}$ Hampton Roads Sanitation District, 1434 Air Rail Avenue, Virginia Beach, VA, 23455, USA.

${ }^{17}$ Southern California Coastal Water Research Project, Costa Mesa, CA 92626, USA.

${ }^{18}$ Institute of Environmental Science and Research Ltd (ESR), Porirua, 5240, New Zealand.

${ }^{19}$ Drexel University, Philadelphia, Pennsylvania, USA.

${ }^{20}$ School of Sustainable Engineering and the Built Environment and The Biodesign Institute Center for Environmental Health Engineering, Arizona State University, Tempe, AZ 85287, USA.

${ }^{21}$ Environmental Health Institute, National Environment Agency, Singapore.

${ }^{22}$ Department of Integrative Biology, University of South Florida, Tampa, FL, USA.

${ }^{23}$ Environmental Interventions Unit, Icddr,b, 68 Shaheed Tajuddin Ahmed Sarani, Mohakhali, Dhaka 1212, Bangladesh.

${ }^{24}$ Water Research Centre, School of Civil and Environmental Engineering, University of New South Wales, NSW 2052, Australia.

${ }^{25}$ Department of Microbiology, Faculty of Science, Stellenbosch University, Private Bag X1,

Stellenbosch, 7602, South Africa. 
${ }^{26}$ Division of Environmental Engineering, Faculty of Engineering, Hokkaido University, North 13 West 8, Kita-ku, Sapporo, Hokkaido 060-8628, Japan.

${ }^{27}$ United States Environmental Protection Agency, Office of Research and Development, 26W Martin Luther King Jr. Drive, Cincinnati, OH, 45268, USA.

${ }^{28}$ Department of Environment and Health, Istituto Superiore di Sanità, Rome, Italy.

${ }^{29}$ Department of Research \& Innovation, Clean Water Services. Hillsboro, OR, USA.

${ }^{30}$ Environmental Health Sciences Department., University of Georgia, Athens, GA, 30602 USA.

${ }^{31}$ School of Freshwater Sciences, University of Wisconsin-Milwaukee, Wisconsin, USA.

${ }^{32}$ KWR Water Research Institute, Groningenhaven 7, 3433 PE Nieuwegein, The Netherlands.

${ }^{33}$ UCD School of Biomolecular and Biomedical Science, University College Dublin, Dublin, Ireland.

${ }^{34}$ Department of Pathobiology, Ontario Veterinary College, University of Guelph, Guelph, ON, Canada.

${ }^{35}$ University of California Merced Department of Civil and Environmental Engineering $5200 \mathrm{~N}$. Lake Rd. Merced, CA 95343.

${ }^{36}$ Sydney Water, 1 Smith Street, Parramatta, NSW 2150, Australia.

${ }^{37}$ Water and Health Pty Ltd., 13 Lord St, North Sydney, NSW, 2060, Australia.

38 School of Medicine, Griffith University, Parklands Drive, Gold Coast, Australia.

${ }^{39}$ Finnish Institute for Health and Welfare, Expert Microbiology Unit, P.O. Box 95, FI-70701 Kuopio, Finland.

40University of Helsinki, Faculty of Veterinary Medicine, Department of Food Hygiene and Environmental Health, P.O. Box 66, FI-00014.

${ }^{41}$ Facultad de Ingeniería and Instituto de Investigaciones para la Industria Química (INIQUI) - CONICET and Universidad Nacional de Salta. Av. Bolivia 5150, Salta, Argentina.

${ }^{42}$ Institute of Environmental Assessment \& Water Research (IDAEA), CSIC, Barcelona, Spain.

${ }^{43}$ Biotechnology Institute and Department of Soil, Water, and Climate, University of Minnesota, St. Paul, MN, USA.

${ }^{44}$ Department of Environmental Health Sciences, Tulane University, 1440 Canal Street, New Orleans, LA, 70112, USA.

${ }^{45}$ Research Laboratory of Biotechnology, Chulabhorn Research Institute, 54 Kampangpetch 6 Road, Laksi, Bangkok, 10210, Thailand.

${ }^{46}$ CSIRO Agriculture and Food, Bioscience Precinct, St Lucia, QLD 4067, Australia.

${ }^{47}$ College of Marine Science, University of South Florida, St. Petersburg, FL, USA.

${ }^{48}$ Department of Civil and Environmental Engineering, Massachusetts Institute of Technology, Cambridge, MA, USA

${ }^{49}$ Asian School of the Environment, Nanyang Technological University, Singapore (NTU), 639798 Singapore.

${ }^{50} \mathrm{CSIRO}$ Land and Water, Floreat, WA, 6012, Australia.

${ }^{51}$ Department of Civil and Environmental Engineering, Graduate School of Engineering, Tohoku University, Aoba 6-6-06, Aramaki, Aoba-Ku, Sendai, Miyagi, 980-8597, Japan.

${ }^{52}$ School of Civil and Environmental Engineering, Nanyang Technological University, Singapore (NTU), 639798 Singapore.

${ }^{53}$ Department of Civil and Environmental Engineering, Michigan State University., East Lansing, MI 48824.

Running title: False-positive and -negative errors in wastewater surveillance

*Corresponding author. Warish Ahmed. Mailing address: Ecosciences Precinct, 41 Boggo Road, Dutton Park 4102, Queensland, Australia Tel.: +617 3833 5582; E-mail address: Warish.Ahmed@csiro.au 


\begin{abstract}
Wastewater surveillance for pathogens using the reverse transcription-polymerase chain reaction (RT-PCR) is an effective, resource-efficient tool for gathering additional communitylevel public health information, including the incidence and/or prevalence and trends of coronavirus disease-19 (COVID-19). Surveillance of SARS-CoV-2 in wastewater may provide an early-warning signal of COVID-19 infections in a community. The capacity of the world's environmental microbiology and virology laboratories for SARS-CoV-2 RNA characterization in wastewater is rapidly increasing. However, there are no standardized protocols nor harmonized quality assurance and quality control (QA/QC) procedures for SARS-CoV-2 wastewater surveillance. This paper is a technical review of factors that can lead to falsepositive and -negative errors in the surveillance of SARS-CoV-2, culminating in recommendations and strategies that can be implemented to identify and mitigate these errors. Recommendations include, stringent QA/QC measures, representative sampling approaches, effective virus concentration and efficient RNA extraction, amplification inhibition assessment, inclusion of sample processing controls, and considerations for RT-PCR assay selection and data interpretation. Clear data interpretation guidelines (e.g., determination of positive and negative samples) are critical, particularly during a low incidence of SARS-CoV-2 in wastewater. Corrective and confirmatory actions must be in place for inconclusive and/or potentially significant results (e.g., initial onset or reemergence of COVID-19 in a community). It will also be prudent to perform inter-laboratory comparisons to ensure results are reliable and interpretable for ongoing and retrospective analyses. The strategies that are recommended in this review aim to improve SARS-CoV-2 characterization for wastewater surveillance applications. A silver lining of the COVID-19 pandemic is that the efficacy of wastewater surveillance was demonstrated during this global crisis. In the future, wastewater will play an important role in the surveillance of a range of other communicable diseases.
\end{abstract}

Keywords: COVID-19; SARS-CoV-2; Wastewater; Surveillance; False-positive; Falsenegative; RT-PCR 


\section{Introduction}

The coronavirus disease-2019 (COVID-19) global pandemic caused by severe acute respiratory syndrome coronavirus 2 (SARS-CoV-2) has resulted in hundreds of millions of diagnosed cases and millions of deaths globally by the end of 2020 (Dong et al., 2020). SARS-CoV-2 is an enveloped respiratory virus with an RNA genome. Typical symptoms of COVID-19 may include any or a combination of the following symptoms: fever or chills, cough, shortness of breath or difficulty breathing, fatigue, muscle or body aches, headache, loss of smell/taste, rhinorrhea, nausea or vomiting, and diarrhea in infected individuals (CDC, 2021). Aside from acute impacts, the virus can also lead to debilitating late sequelae (CDC, 2020). COVID-19 is most commonly detected in symptomatic individuals by collecting nasopharyngeal or throat swabs (Wölfel et al., 2020) and analyzing for SARS-CoV-2 using reverse transcription-polymerase chain reaction (RT-PCR) assays, however, antibody- and/or antigen-based tests are also used as a clinical surveillance tool (Ward et al., 2020). Notably, not all COVID-19 infected individuals develop the typical symptoms described above (Nishiura et al., 2020). Asymptomatic individuals may account for approximately $40-50 \%$ of infections (Oran and Topol, 2020). These individuals can transmit the virus to others in the community for $>14$ days (Gandhi et al., 2020; Oran and Topol, 2020).

Symptomatic and asymptomatic COVID-19 patients shed SARS-CoV-2 in feces, saliva, nasal secretions and urine (Cevik et al., 2020). One study found that analysis of fecal samples for SARS-CoV-2 can be more sensitive to infection than using samples from the respiratory tract, as feces carried a greater viral load, and positive results were consistently obtained over the course of the disease (Yuan et al., 2021). Intact or degraded SARS-CoV-2 viruses and RNA fragments reach sewer networks through toilets, showers, wash basins and sinks and can subsequently be detected in wastewater, both at the sub-catchment scale and in the influent to wastewater treatment plants (WWTPs). Recent studies have highlighted the potential application of SARS-CoV-2 RNA surveillance in untreated wastewater could provide information on the early detection or act as an advance warning system for the circulation of COVID-19 in a community (Ahmed et al., 2020a; Ahmed et al., 2020b; La Rosa et al., 2020; Medema et al., 2020; Miyani et al., 2020; Randazzo et al., 2020; Rimoldi et al., 2020; Wu et al., 2020; Chavarria-Miro et al., 2021; Gerrity et al., 2021). A caveat common to all methods based solely on molecular detection is that wastewater surveillance measures the presence and quantity of SARS-CoV-2 RNA, not the viable or infectious viruses from the individual building level to large metropolitan areas (i.e., WWTP influents).

This surveillance approach is currently being used worldwide as a complementary tool to monitor SARS-CoV-2 RNA in wastewater (Bivins et al., 2020). Wastewater surveillance is not entirely novel, nor is the concept restricted to COVID-19, e.g., wastewater surveillance for poliovirus is a past and current practice (Asghar et al., 2014; Alleman et al., 2021). SARSCoV-2 wastewater surveillance is currently practiced in at least 50 countries (Supplementary Fig. 1). Over 230 organizations have announced that they are analyzing wastewater samples for SARS-CoV-2 RNA, with samples being sourced from $>1,370$ sites (including WWTPs, sewer catchments and surface waters) (Naughton et al. 2021; https://arcg.is/1aummW).

Potential benefits of wastewater surveillance, including the detection of pre- and asymptomatic cases and the possibility to screen large populations with a single or small number of samples, independent of clinical testing availability and willingness (Thompson et al., 2020). With strategic facility-specific or sub-catchment sampling, SARS-CoV-2 surveillance can also identify hotspots within large geographic regions, and this information can facilitate focused and prompt action by local health authorities (Stadler et al., 2020). Actions arising from positive results of wastewater surveillance might include potential public announcements to encourage individual testing, increasing the availability of testing, establishing fever clinics in specific targeted locations, implementing stay-at-home directives, or mandating other mitigation measures such as face masks, social distancing, and capacity limits to reduce transmission (Randazzo et al., 2020). An important aspect of wastewater 
surveillance is the ability to rapidly and cost-effectively gather data from a large population of thousands of individuals, with enough sensitivity to potentially detect a small number of infected individuals contributing SARS-CoV-2 RNA into the local wastewater system (Michael-Kordatou et al., 2020). This "pooling concept" can be particularly important for regions with low clinical COVID-19 testing rates, minimal resources, or no known cases.

Wastewater surveillance of SARS-CoV-2 RNA involves a sequence of steps

(Supplementary Fig. 2), commencing with sampling from a location within a wastewater system (i.e., maintenance holes, pumping/lift stations or facility influent) or at outlets of buildings, followed by virus concentration, extraction of RNA, use of RT-PCR for molecular detection and quantification (RT-qPCR; based on a standard curve or RT-dPCR; digital PCR without the need for a standard curve) of SARS-CoV-2 RNA, and data analysis and interpretation. Many factors can affect the overall method performance and the reliability of results (Ahmed et al. 2020d; Bustin et al., 2009; Medema et al., 2020b; Pecson et al., 2021). An optimized RT-PCR assay is theoretically capable of detecting a single SARS-CoV-2 RNA fragment (Bustin et al., 2009). Such high sensitivity is particularly useful for the surveillance of SARS-CoV-2 in wastewater where the RNA target concentration can be extremely low $(\sim 20$ to 2,000 GC/L) (Ahmed et al., 2020a; Haramoto et al., 2020). However, increasing analytical sensitivity coupled with poor assay specificity of a RT-PCR method has the potential to increase the chance of false-positive errors. A false-positive is defined here when a RT-PCR result is positive for a SARS-CoV-2 RNA target when it is actually not present in the wastewater sample.

While false-positive errors can be monitored, minimized, and eliminated through strict adherence to best laboratory practices with appropriate controls, false-negative outcomes are more difficult to identify and manage. A false-negative error occurs when a RT-PCR result is negative for SARS-CoV-2, but the target RNA is actually present in the wastewater sample. False-negative errors may arise from a variety of factors including that are inherent to a particular wastewater sample and how it is collected, transported and stored (i.e., freezing), low abundance of RNA target in wastewater, degradation of the RNA target in the sewer collection system. Other factors are related to sample processing and analysis, such as poor virus recovery and/or low effective sample volume (ESV) assayed, low RNA extraction efficiency, amplification inhibition in the RT-PCR assay, and poor diagnostic assay sensitivity (Ahmed et al., 2020d; Medema et al., 2020b; Michael-Kordatou et al., 2020).

In this paper, we discuss: (i) implications of SARS-CoV-2 false-positive and false-negative errors for public health responses; (ii) factors that may contribute to the occurrence of falsepositive and false-negative errors of SARS-CoV-2 RNA in untreated wastewater across the entire process; and (iii) strategies that can be used to minimize the impacts of false-positive and false-negative errors on stakeholder confidence in SARS-CoV-2 wastewater surveillance. This review provides a basic scientific framework that can aid in setting and developing appropriate quality control measures around sampling and laboratory workflow with regards to wastewater surveillance for SARS-CoV-2 and other pathogens.

\section{Definition of false-positive and -negative errors in the wastewater surveillance context}

Typically, for an analytical test such as RT-PCR, false-negative and -positive errors are interpreted only for the presence or absence of the relevant analyte in the sample, such as mentioned above. However, during wastewater surveillance, such as for SARS-CoV-2, RTPCR results are interpreted relevant to two parameters: (i) the presence or absence of SARSCoV-2 RNA in a wastewater sample; and (ii) the presence or absence of SARS-CoV-2 infections in the community. For this reason, there are two layers of error that must be considered. The first layer, which we term RT-PCR false-positive or RT-PCR false-negative is pertinent to whether SARS-CoV-2 RNA is present or absent in a wastewater sample, and whether test results accurately reflect these conditions. The second layer, which we term 
wastewater surveillance false-positive or false-negative, is pertinent to whether SARS-CoV-2 infection is present or absent in the community. In the ideal application of wastewater surveillance, an RT-PCR positive indicates that SARS-CoV-2 RNA is present in wastewater, and subsequently, an infection is found to be present (via clinical testing) in the community, which is a true positive for both RT-PCR and wastewater surveillance. Or, conversely, an RTPCR negative indicates that SARS-CoV-2 is absent in wastewater, and subsequently, SARSCoV-2 infection is absent from the community, which corresponds to a true negative for both RT-PCR and wastewater surveillance.

Concordant and discordant false-negative and -positive errors can occur for both layers of interpretation. SARS-CoV-2 infection could be present in the community, but the wastewater sample doesn't contain detectable levels of SARS-CoV-2 RNA, so an RT-PCR negative result would be an RT-PCR true negative but a wastewater surveillance false negative. Or, SARSCoV-2 infection could be absent in the community but the wastewater sample contains SARS-CoV-2 RNA owing to cross-contamination, so an RT-PCR positive result could be an RT-PCR true positive but a wastewater surveillance false positive. The occurrence of falsepositive and -negative errors are not well documented in wastewater surveillance applications. These errors can lead to erroneous decision-making by public health officials.

\section{Factors contribute to SARS-CoV-2 RT-PCR false-positive errors in wastewater surveillance}

False-positive errors can arise from the introduction of contamination in field samples (Westhaus et al., 2020), the laboratory (Tahamtan and Ardebili, 2020), or even in the assay reagents (Mögling et al., 2020). They can also arise from poorly designed RT-PCR primers and probes that detect non-target RNA not associated with SARS-CoV-2 (Westhaus et al., 2020). This section will review potential sources of false-positive errors, which are typically identified by the inclusion of controls at various stages of the sampling and laboratory workflows, and by sequence confirmation of amplified products.

\subsection{Contamination in the field}

The process of wastewater collection presents multiple opportunities to contaminate samples that could result in false-positive errors. SARS-CoV-2 RNA can persist in untreated wastewater and tap water for up to approximately ten days, at $37^{\circ} \mathrm{C}$ or approximately $30-60$ days, respectively at $4^{\circ} \mathrm{C}$ (Ahmed et al., 2020C). In regions with a high prevalence of COVID19, SARS-CoV-2 RNA has been found on general surfaces in public places (Gholipour et al., 2020). Therefore, SARS-CoV-2 RNA can potentially accumulate on the surface of sampling equipment (e.g., tubes attached to autosamplers, contaminated sampling bottles) as well as sampling gear (e.g., telescopic sampler, pump, and multi-meters). As a result, wastewater samples could become contaminated due to inadequate cleaning between equipment uses. A false-positive can also occur when handling multiple samples at an individual collection location (near the influent or maintenance hole etc.) due to gloves and clothing being contaminated by accidental splashes or possibly aerosols. Improper storage during transport to the laboratory also could cause cross-contamination. Ice accidentally contaminated with positive samples could potentially transfer SARS-CoV-2 RNA to another sample if the bottle lids are not properly sealed.

\subsection{Contamination in the laboratory workflow}

Sample to sample contamination may also occur in the laboratory during sample processing and storage (i.e., in a cold room or a refrigerator), sample concentration, RNA extraction from positive samples, from positive control material (i.e., synthetic fragments, gamma-irradiated or heat-inactivated SARS-CoV-2 reference materials), and/or RT-PCR amplification steps and amplicons generated from previous SARS-CoV-2 positive samples. Cross-contamination from 
an analyst's personal protective equipment to laboratory surfaces has been identified in using RT-droplet digital PCR (RT-ddPCR) assays (Lv et al., 2020).

A shortage of skilled laboratory personnel due to the high demand for analysts has resulted in less experienced individuals in a laboratory, exacerbate cross-contamination issues and false-positive errors (Albano et al., 2020; Giri et al., 2020). Such issues may affect not only clinical diagnostics but also wastewater surveillance, especially in areas with a low prevalence of COVID-19. Some laboratories are being requested to analyze large numbers of wastewater samples (up to 100 or more per week) for routine surveillance, and the testing rates may increase (Pers. Comm. Phil Choi, Queensland Health). As the interest grows in routine wastewater surveillance, a faster turnaround of results is desired by public health units that utilize the data for management actions. Both factors (sample numbers and turnaround time) place increased pressure on laboratory personnel, which may lead to increased frequencies of errors, resulting in an increase in contamination and false-positive errors.

\subsection{Commercial reagent contamination}

False-positives can also originate from RT-PCR reagents themselves or due to poor assay specificity. The notion that commercial PCR reagents can contain unwanted contamination is not new. There are numerous reports of $E$. coli fragments in DNA polymerase preparations (Koponen et al., 2002), as well as human mitochondrial DNA fragments in deoxyribonucleotide preparations (Wilson et al., 2016). These contaminants are introduced during the manufacturing of the reagents and, in some instances, can lead to false-positive errors. False-positive errors of SARS-CoV-2 assays in clinical specimens have been reported in Europe, where several laboratories identified contaminated commercial primer and probe reagent batches with synthetic control materials (Mögling et al., 2020). Fig. 1 shows RT-PCR results of RNA extracted from 11 SARS-CoV-2 wastewater samples, method blank, no template controls (NTCs), and positive controls (i.e., gamma-irradiated SARS-CoV-2) using the $\mathrm{N}$ gene assay. This illustrates that a potential false-positive error cannot be distinguished from the positive control if an appropriate method blank and NTCs are not used. In this case, the contamination was traced back to three preparations of primer and probe mix purchased from a vendor after analyzing multiple replicates of primer and probe mix.

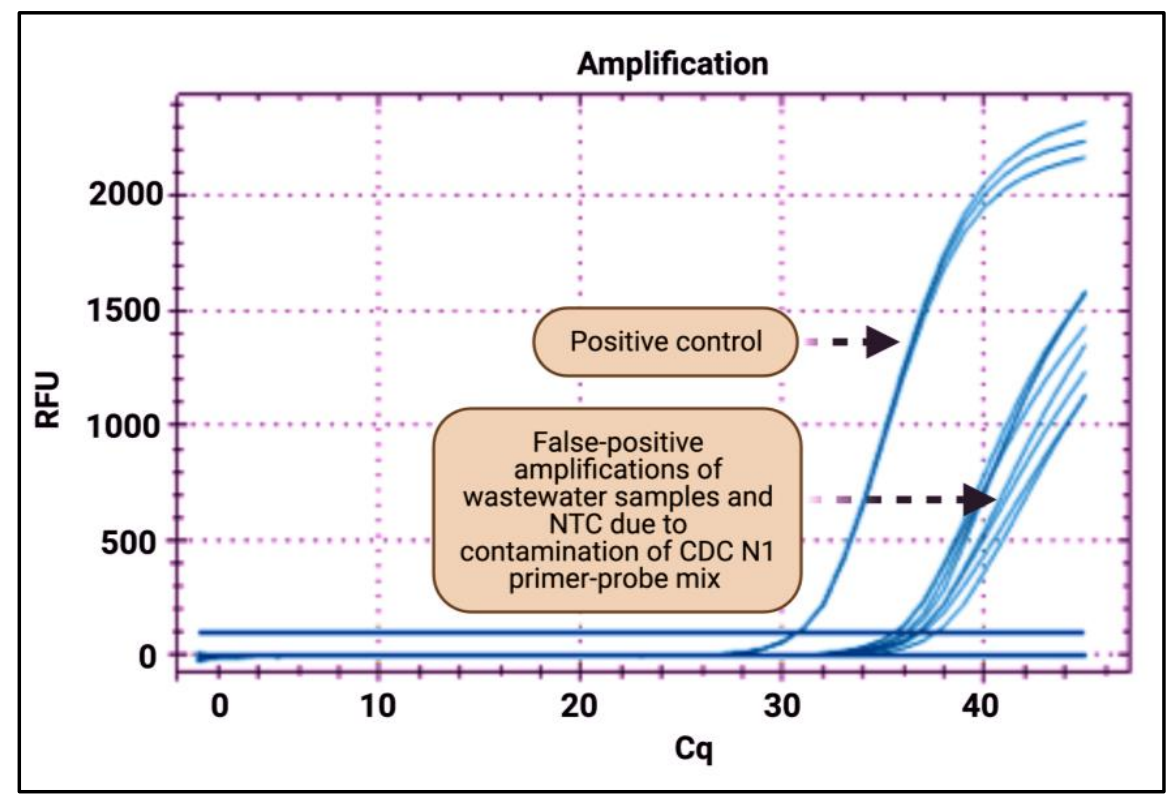


Fig. 1: An example of false-positive RT-PCR results for SARS-CoV-2. RNA extracted from 11 SARS-CoV-2 wastewater samples, method blank controls, no template controls (NTCs), and positive controls (i.e., gamma-irradiated SARS-CoV-2 genome) were amplified using the $\mathrm{N}$ gene assay. Three of the 11 samples, the method blank and NTC were positive amplifications. The contamination was traced back to the primer and probe mix purchased from the vendor by analyzing multiple replicates from the tubes in the same batch. RFU: Relative fluorescence units. Data source: CSIRO molecular microbiology laboratory, Queensland, Australia (unpublished data).

\subsection{Assay specificity}

Improper selection of SARS-CoV-2 target genes or design of primers and probes that are not specific to the target may also lead to false-positive errors. For example, Westhaus et al. (2020) noted that certain SARS-CoV-2 RT-PCR assays targeting the RdRP or M-gene, may also detect other endemic human coronaviruses, and lead to a false-positive error of SARSCoV-2. Gerrity et al. (2021) reported an instance of cross-reactivity between the E_Sarbeco assay and seeded bovine coronavirus. Pecson et al. (2021) reported significant crossreactivity between a human coronavirus OC43 assay and seeded bovine coronavirus - two common SARS-CoV-2 surrogates used as process controls. It is thus essential that the specificity (i.e., amplification of only the target SARS-CoV-2 gene) of the selected SARSCoV-2 target sequence and the oligonucleotides are adequately assessed to increase confidence in SARS-CoV-2 detection and identify potential false-positives errors.

Confirmation of assay specificity will be particularly relevant as assays for emerging new SARS-CoV-2 variants of concern target new genomic regions that have not been previously vetted for specificity and primer-dimer formation.

\section{Factors contribute to SARS-CoV-2 RT-PCR false-negative errors in wastewater surveillance}

SARS-CoV-2 false-negative errors in wastewater surveillance can result from inefficient RNA recovery in samples, PCR inhibition, or methods that are not optimized to detect trace quantities of target RNA. This section will review known and possible sources of falsenegative errors for RT-PCR wastewater surveillance applications.

\subsection{Variable shedding and low prevalence of SARS-CoV-2 infection in a community} Individuals infected with SARS-CoV-2 shed the virus and its genetic material via their sputum, nasopharyngeal secretions, saliva, urine, and feces (Cevik et al. 2020). The concentration of the SARS-CoV-2 in the feces of infected individuals is highly variable and ranges from $10^{2}$ to $10^{9} \mathrm{GC} / \mathrm{g}$ of feces (Wölfel et al., 2020; Zhang et al., 2020). It has also been reported that SARS-CoV-2 RNA detection rate can range from 11 to $83 \%$ in the feces of COVID-19 positive adults (Wölfel et al., 2020) and 100\% in the feces of children (Xu et al., 2020). As the prevalence of COVID-19 within a community decreases, the number of individuals shedding the virus in feces, urine and nasal secretions and the subsequent amount of RNA shed into the sewer system will also decrease, thus reducing the amount of virus entering the wastewater system.

Low and sporadic occurrence of SARS-CoV-2 RNA in wastewater due to low COVID-19 cases in the community makes it more challenging to detect and is critical to take steps that minimize false-negative errors. Furthermore, the effects of RNA target dilution, in large part due to mixing with other wastewater flows, stormwater infiltration, the diurnal variation in shedding, and hydraulic residence time in the sewer collection system, can also affect the probability of detection of SARS-CoV-2 RNA, particularly in low prevalence conditions (Ahmed et al. 2020d). As a result, in communities where SARS-CoV-2 infection is low, RNA is less likely to be detected in wastewater. For example, in Australia, in late 2020 and early 2021, COVID-19 clinical test positivity was $~ 0.2 \%$ (Australian Government Department of Health; February 2021), and wastewater surveillance in some areas frequently resulted in non-detects for SARS-CoV-2. In contrast, test positivity in much of the United States still exceeded 5\% in early 2021 (CDC, 2021; https://www.cdc.gov/coronavirus/2019-ncov/covid- 
data/covidview/index.html) leading to consistent detection of SARS-CoV-2 (Gonzalez et al., 2020; Gerrity et al., 2021; Wu et al., 2021).

\subsection{Variability in wastewater composition}

Despite mixing and dilution in sewer systems, it is incorrect to consider sewage, as it arrives at a WWTP to be composed of a well-mixed liquor of everything discharged to the system during a day (Teerlink et al., 2012). Instead, sewers are dynamic flow systems, and the composition of wastewater arriving at a WWTP changes continually, reflecting variation in flow rates and substances discharged into the sewer system (Ort et al., 2010b). Some sewer systems have the capacity to provide a degree of lateral flow mixing, such as those with storage capacity associated with pumping stations or flow equalization tanks. Turbulent flow regimes in sewer pipes can also induce lateral mixing, but this homogenization is often limited and may not be substantial relative to the overall volumes of wastewater conveyed.

For a substance that is constantly or frequently discharged into a sewer network in relatively constant amounts, any random wastewater sample could reasonably be used to estimate a daily load. However, for a substance that is sporadically discharged into sewers in varying amounts temporally, either continuous sampling or multiple samples collected at different times of day will be required to accurately estimate the total daily load (Ort et al., 2010a). Discontinuous surveillance using grab samples imparts a high probability of a falsenegative error occurring or even disproportionately high concentrations that do not accurately reflect conditions in the broader community. Under low-prevalence conditions, if a sample is not collected at the precise moment that the wastewater 'slug' containing a target substance (i.e., SARS-CoV-2 RNA) passes through the sampling point, 'non-detection' may occur (Ort et al., 2010b). This concept is illustrated in Fig. 2, showing that some random sewage volumes (orange ellipses) may contain detectable SARS-CoV-2 RNA, while others (brown matrix) may not.

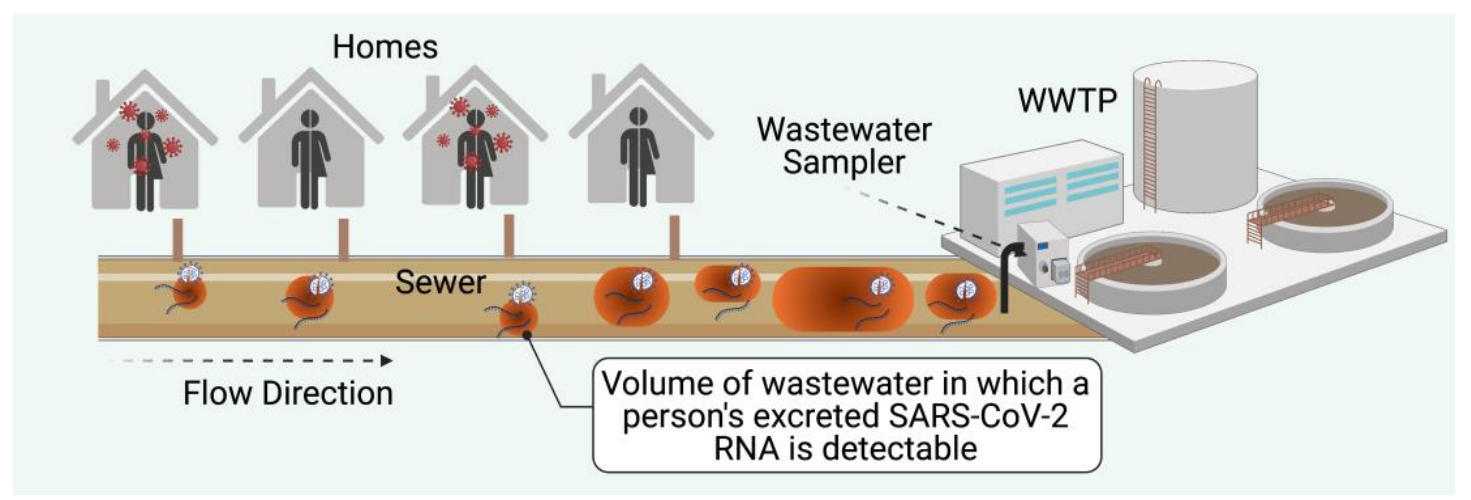

Fig. 2: Under low-prevalence conditions, some random sewage volumes (orange ellipses and circles) contain detectable SARS-CoV-2 RNA, while others (brown matrix) do not.

If a single grab sample is collected, the likelihood of it containing any of the daily SARS-CoV2 RNA excretions of an individual person depends on the total daily volume of wastewater and the volume into which that individual's excretions may be dispersed. From an analytical perspective, the likelihood of detection also depends on the concentration of that individual's SARS-CoV-2 RNA excretions and the method limit of detection (MLOD; definition is given in section 4.9). If no lateral mixing of wastewater has occurred, the SARS-CoV-2 will be present at high concentrations in only the wastewater volume into which it was discharged, such as a toilet flush. If a very large degree of lateral mixing has occurred (into many thousands or millions of $\mathrm{L}$ ), the RNA concentration may be below the MLOD. Consequently, the degree of 
lateral mixing, the substance dispersion volume, and MLOD are important factors determining the likelihood of a positive sample detection.

We used a simplified conceptual model to demonstrate the challenges of detecting SARSCoV-2 RNA in a sewer system when the percentage of individuals excreting SARS-CoV-2 is relatively low. In the model scenario, a sewage system serving a population of 100,000 people with an average dry weather sewage flow of $0.2 \mathrm{~m} 3 /$ person/day will produce wastewater at a rate of $20,000 \mathrm{~m}^{3} /$ day. The probability that any single grab sample (relative to the detectable dispersion volumes) contains a detectable concentration of a specific individual's excreted SARS-CoV-2 can be estimated by the ratio of the average detectable dispersion volume $\left(\mathrm{m}^{3} /\right.$ day) and the average dry weather flow $\left(\mathrm{m}^{3} /\right.$ day). A detectable dispersion volume is the volume of wastewater that a person's total daily excretions are dispersed into while remaining above the MLOD. Hypothetical values of 1,10 , or $100 \mathrm{~m}^{3}$ were chosen to illustrate this point; detectable dispersion volumes will vary depending on the parameters of different sewer systems (e.g., SARS-CoV-2 RNA persistence given sewer travel times and temperatures, and mixing). The implication is that for a larger detectable dispersion volume, there is a greater likelihood of a positive detection.

Since the dispersion volumes of multiple individuals may overlap, the probability $\mathrm{P}(x)$ of any small sample containing the detectable excreted RNA from any number of multiple individuals can be described by the binomial distribution $\mathrm{P}(x) \sim \mathrm{B}(n, p)$, where $x$ is the specified number of individuals for which excreted RNA can be detected in that sample, $n=$ the number of individuals shedding SARS-CoV-2 RNA, and $p=$ the probability that the sample contains a detectable concentration of a specific individual's excreted SARS-CoV-2 RNA (as given by the ratio above).

$$
P(x)=\left(\frac{n !}{x !(n-x) !}\right) p^{x}(1-p)^{n-x}
$$

Assuming a sewer catchment population of 100,000 people, an average dry weather wastewater flow of $0.2 \mathrm{~m}^{3} /$ person/day and an average detectable dispersion volume of each person's excretions of $1 \mathrm{~m}^{3}, 10 \mathrm{~m}^{3}$ or $100 \mathrm{~m}^{3}$, the probability of a single wastewater sample being negative for SARS-CoV-2 RNA is given by the binomial distribution solution for $P(x=0)$, as shown in Fig. 3a. If the proportion of people shedding SARS-CoV-2 is $<0.01 \%$, the likelihood of a grab sample not containing the RNA at a detectable concentration is above $90 \%$ for all three assumed mixing scenarios. In this case, $\mathrm{x}=0, \mathrm{n}<10$ people per 100,000 , and $p$ is dependent upon the average detectable dispersion volume of each person's excretions.

In any of the circumstances considered in Fig. 3a, the likelihood of collecting a positive sample can be increased by collecting a larger number of grab samples. In this case, the probability $(\mathrm{P})$ of never collecting a sample containing RNA $\mathrm{P}(x=0)$, can be modelled as an outcome of a second binomial distribution $\mathrm{B}(n, p)$, where $n=$ the number of samples collected and $p=$ the probability of any sample being positive. The probability (\%) of all samples being negative for $n=1,10,100$ or 1,000 samples, where the average dispersion volume is assumed to be $10 \mathrm{~m}^{3}$, is presented in Fig. 3b. It can be observed that for a population with $0.1 \%$ shedding RNA, collection of 10 grab samples over a $24-\mathrm{h}$ period gives $<50 \%$ likelihood of returning one or more samples that contain the virus. For a population with only $0.01 \%$ shedding SARS-CoV-2, around 140 grab samples are required to give a $50 \%$ chance of a sample containing RNA. Thus, capture of RNA and subsequent detection can be difficult if only a small proportion of the population are shedding SARS-CoV-2. 

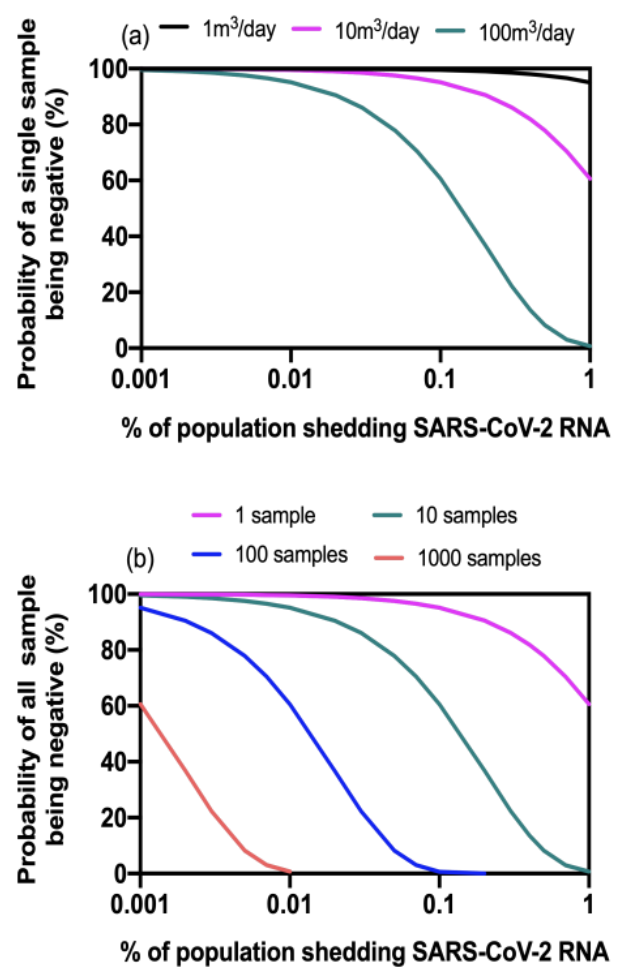

Fig. 3a: Probability of a single small sample (relative to SARS-CoV-2 dispersion volume) being negative, assuming a sewer catchment population of 100,000 people, average dry weather flow $0.2 \mathrm{~m} /$ person/day, and dispersion volumes of $1 \mathrm{~m}^{3} /$ day, $10 \mathrm{~m}^{3} /$ day or 100 $\mathrm{m}^{3} /$ day. 3b: Probability of all samples being negative for $n=1,10,100$ or 1000 samples.

In lieu of analyzing a large number of samples, an equivalent composite sample could be used to produce similar probability outcomes, assuming that the degree of dilution provided by the 'negative' composite sub-samples did not reduce the RNA concentration from 'positive' composite sub-samples to $<M L O D$. These observations are only significant in circumstances where SARS-CoV-2 RNA is assumed to be a sporadically discharged substance. That assumption only applies where the proportion of concurrent excreters is very low. However, it may be relevant in any circumstance where wastewater surveillance is undertaken for the purpose of providing an 'early warning' of re-emergence of COVID-19, following near elimination of the virus. In such cases, it is important to recognise that failures to detect RNA in wastewater do not provide infallible evidence that RNA and COVID-19 infected people are not sporadically present in wastewater and in the community, respectively.

The model presented here is purely conceptual to illustrate the considerations for achieving a representative sample of wastewater surveillance for SARS-CoV-2. Also, the model input parameters and outcomes may vary greatly considering different types of sewer systems and shedding rates. An additional consideration is that the actual behavior of SARSCoV-2 in wastewater collection systems remains poorly characterized. Enveloped viruses have been observed to partition favourably to solids, which likely changes their transport behavior from that of dissolved species, which are frequently used to characterize fate and transport in hydraulic systems (Ye et al., 2016). The adsorption of SARS-CoV-2 to surfaces, such as suspended solids, is dependent on both surface chemistry and solution chemistry, which further complicates idealized conceptualization of the fate and transport in wastewater (Liu et al., 2021). Additionally, SARS-CoV-2 and its RNA have been observed to exist in several different forms in wastewater including both intact and ruptured viruses (Wurtzer et al., 2020). 


\subsection{Sampling approach matters}

Since the first pre-print paper on the detection of SARS-CoV-2 in wastewater (Medema et al., 2020a), the selection of the best sampling strategy has been a challenge for wastewater surveillance studies. As described above, inadequate wastewater sampling strategies can easily contribute to false-negative errors (regardless of how good the laboratory workflow is) (Ahmed et al., 2020d). Common sampling approaches include grab samples, which may be individual sample or composites of several grabs or the use of an auto-sampler to collect a composite sample over a longer time period, frequently 24-h (WHO, 2003; Miyani et al., 2020) or the use of passive samplers where an absorbent materials such as swabs or medical gauze is placed in the wastewater and retrieved after hours and days, is a low-cost alternative to autosamplers (Schang et al., 2021).

In most scenarios, samples created from a composite of multiple sub-samples offer a more representative measure of the viral concentration in wastewater (Matrajt et al., 2018). Ahmed et al. (2020e) demonstrated the higher variability of grab samples compared to composite samples for both indicator and pathogenic viruses in untreated wastewater. Gerrity et al. (2021) noted that early-morning grab samples generally had lower concentrations than corresponding 24-h composite samples, and that study also demonstrated the potential benefits and trade-offs of sampling primary effluent, by which point wastewater flows have undergone greater mixing or dispersion but also significant dilution of peak loads.

Composite auto-samplers deployed at fixed sampling locations are becoming the most favoured sampling approach in high-income countries (Hamouda et al., 2021). Depending on the wastewater system, either time-weighted or flow-weighted composite sampling may be more effective for capturing concentration spikes of pharmaceuticals and personal care products (Ort et al., 2010b). Only where wastewater is homogenized, and dilution is limited may grab sampling result in representative samples, e.g., sampling from wastewater systems of airplanes and cruise ships (Ahmed et al. 2020f; Albastaki et al., 2021). Sampling of small sewer networks (e.g., buildings or neighbourhoods), where few toilet flushes occur over the course of a day and large short-term fluctuations are expected, would require an increased sampling frequency or peak sampling, e.g., during the morning hours, to capture these shedding events (Aymerich et al., 2017). Passive samplers may be useful alternatives in such cases as they have a demonstrated ability to accumulate pathogens over time, often with greater sensitivity and efficiency than grab samples. Passive samplers are much less costly and easier to deploy in drains than setting up and operating autosamplers (Lund and Hedström, 1969; Schang et al., 2021).

Sampling upstream of the WWTP at maintenance holes or pump station sites, or even building-level surveillance such as on university campuses, can detect local "hot spots" that may be missed in WWTP influent samples due to viral RNA dispersion and dilution. This high spatial resolution sewer catchment data could be valuable when maintenance holes drain areas with industrial activities prone to COVID-19 outbreaks, such as food processing plants, quarantine facilities, hospitals, or high-density living areas such as college dormitories.

However, the intermittent nature of the signal becomes more pronounced as the catchment area gets smaller, so high-frequency composite sampling or the use of passive samplers that sample for a prolonged period becomes especially important in these sampling schemes (Harris-Lovett et al. 2021). Stormwater inflow and infiltration can further dilute viral signals in sewer catchments, particularly in combined sewer systems, and loadings from industries and agriculture can potentially lead to false-negative errors.

\subsection{Pre-treatment and storage of wastewater samples}

It is recommended that concentration of wastewater samples should be performed in a BSL-2 or BC2 laboratory with unidirectional airflow and BC3/BSL-3 precautions (CDC, 2019). Heat pre-treatment pasteurization can be used to minimize exposure risk and help ensure safe sample handling, especially in instances of sample manipulations that may generate aerosols (i.e., sample concentration) (Whitney et al., 2020; Wu et al., 2020). However, temperature, in general, can significantly influence microbial decay (Espinosa et al., 2020; Korajkic et al., 2019; Muirhead et al., 2020), with extended survival (minimal degradation) typically observed at lower temperatures $\left(<15^{\circ} \mathrm{C}\right)$.

A recent study by Ahmed et al. (2020c) indicated that temperature is also the main driver of enveloped virus (MHV and gamma-irradiated SARS-CoV-2) RNA decay in wastewater, 
with decay rates increasing at $25^{\circ} \mathrm{C}$, and being much greater at $37^{\circ} \mathrm{C}$ when compared to 4 or $15^{\circ} \mathrm{C}$. With respect to cold temperatures, a recent study demonstrated that 28 days storage at $4^{\circ} \mathrm{C}$ caused linear decay of SARS-CoV-2 RNA, and thus a risk for false-negative errors; however, samples stored at $-20^{\circ} \mathrm{C}$ or $-80^{\circ} \mathrm{C}$ did not appreciably (Hokajärvi et al., 2021). The nature of the COVID-19 pandemic created situations where the need to immediately collect and analyze samples is urgent, especially in areas where COVID-19 cases are on the rise. It is not always possible to immediately analyse samples, therefore short or long-term storage of samples prior to analysis may be necessary. A strategy based on the other microbial analyses could be storage up to seven days at $4^{\circ} \mathrm{C}$, and for longer terms at freezing temperatures of $-20^{\circ} \mathrm{C}$ or $-80^{\circ} \mathrm{C}$. However, it is not clear whether storing bulk samples would lead to a high rate of false-negative errors and this requires further investigation.

Findings from the limited studies available on pasteurization or cold storage of wastewater samples are somewhat discordant. For example, in Whitney et al. (2020), no significant reduction in SARS-CoV-2 RNA signal was observed when wastewater samples were pasteurized at $70^{\circ} \mathrm{C}$ for $45 \mathrm{~min}$, suggesting that at least some heat pre-treatment conditions may not adversely affect the results. In contrast, the effect of pasteurization was determined at $70^{\circ} \mathrm{C}$ for $40 \mathrm{~min}$ on SARS-CoV-2 $\mathrm{N}$ gene concentrations in triplicate wastewater collected from three WWTPs in Southern California, USA (Fig. 4). Significant reductions in N1 and N2 concentrations were observed, reduced by 1 to $3 \log _{10}$ when sample were concentrated by membrane adsorption coupled with the bioMerieux magnetic bead extraction kit (Fig. 4). Trends were found to be consistent between the three WWTPs.
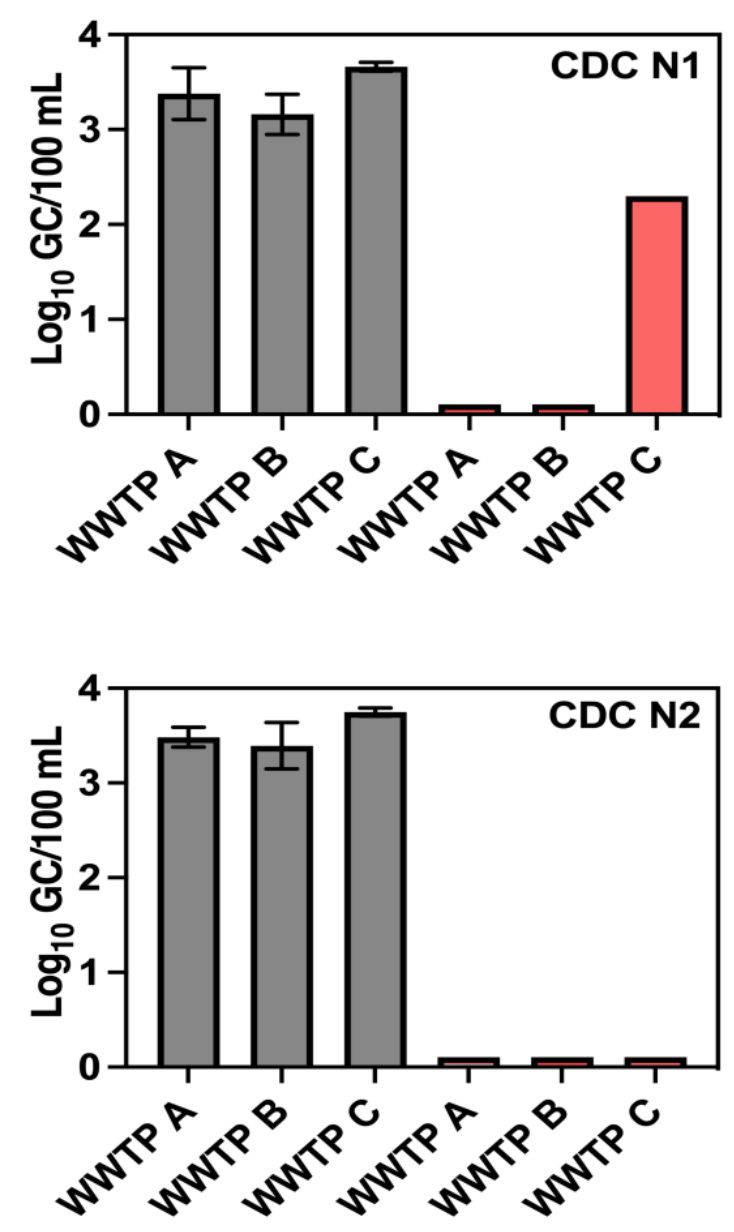
Fig. 4. SARS-CoV-2 concentrations measured by RT-PCR in wastewater samples that were untreated (grey bars) or pasteurized (salmon bars). N1 and N2 levels were determined using adsorption-extraction method. The mean concentration in pasteurized samples was censored; values that were detected but not quantifiable (DNQ) were replaced with half the limit of quantification for statistical analysis. Samples that in which the target was not detected (ND) samples were assigned a value of 1.0. Data obtained partially from Steele et al. (2021).

Storage of wastewater samples at freezing temperatures results in a freeze-thaw cycle for the virus particles and can lead to the degradation of the SARS-CoV-2 RNA thus influencing the assay sensitivity, and consequently, the false-negative rates. Some researchers have reported $\sim 90 \%$ loss of SARS-CoV-2 RNA signal following storage at $-80^{\circ} \mathrm{C}$ for one week (Weidhaas et al., 2020). However, longer storage at freezing temperatures seems not to cause additional loss of the SARS-CoV-2 RNA signal, i.e., no appreciable decay within 58 days at low and ultralow temperatures (Hokajärvi et al., 2021). A recent study also reported no significant decay of OC43 RNA signal, (another betacoronavirus, and a recognized SARSCoV-2 surrogate) at $-80^{\circ} \mathrm{C}$ over three weeks following multiple freeze-thaw cycles in an elution solution (containing $0.01 \%$ sodium hexametaphosphate, $0.01 \%$ Tween 80 and $0.001 \%$ Antifoam Y-20) (McMinn et al., 2021). Together, these studies suggest that while freeze-thaw is a potential contributor to SARS-CoV-2 signal decay, the storage state and conditions are likely important and contribute to the magnitude of signal loss.

\subsection{Concentration strategies}

Viral pathogens are typically dilute in wastewater, necessitating sampling of large volumes (e.g., $>1 \mathrm{~L}$ ) followed by a concentration step to obtain detectable amounts of viral nucleic acid (Ahmed et al., 2015). Efforts to concentrate SARS-CoV-2 RNA from wastewater samples can be a potential source of false-negative errors due to losses incurred during the process. Several authors have reviewed and compared the concentration approaches used for enveloped viruses and particularly for SARS-CoV-2 surveillance in wastewater (Ahmed et al., 2020e; Barril et al., 2021; Cervantes-Aviles et al., 2021; Philo et al., 2020; Rusiñol et al.,2020).

The majority of available SARS-CoV-2 concentration methods have been limited to processing wastewater volumes of 15 to $250 \mathrm{~mL}$, using size exclusion (Gonzalez et al., 2020; Jafferali et al., 2020), membrane adsorption (Jafferali et al., 2020), chemical precipitation (Wang et al., 2005; Randazzo et al., 2020; Torii et al., 2020), ultracentrifugation (Prado et al., 2020) or combinations of these methods (Ahmed et al., 2020d; Gerrity et al., 2021; Pecson et al., 2021). The process detailed by Miyani at al. (2020) is the only large volume concentration method documented in the literature concentrated SARS-CoV-2 from $45 \mathrm{~L}$ of wastewater using electropositive cartridges onsite, followed by elution and centrifugation, however this method is time consuming and laborious.

Most of these techniques were originally developed for the concentration of nonenveloped enteric viruses, whose physiology and capsid structures are significantly different from enveloped respiratory viruses such as SARS-CoV-2 (Philo et al., 2021). The recovery of enveloped viruses from wastewater using these methods can be highly variable, with recoveries ranging from 2-66\% (McMinn et al., 2021). Furthermore, recovery efficiency of SARS-CoV-2 RNA from wastewater samples can vary temporally and from site to site even with the same concentration method due to different composition of wastewater (Fig. 5). The recovery efficiency varied within ( 25 to $77 \%$ ) and across ( $~ 5$ to $72 \%) 20$ WWTP facilities suggesting that the risk for a false-negative error may vary over time and between geographic locations. The propensity to observe false-negatives is further exacerbated by working with small wastewater sample volumes $(\leq 100 \mathrm{~mL})$ and likely represents a major limitation for many currently used wastewater concentration methods, and consequently may be a significant 
impediment to wastewater surveillance applications where virus levels are low, and the recovery efficiency is highly variable.

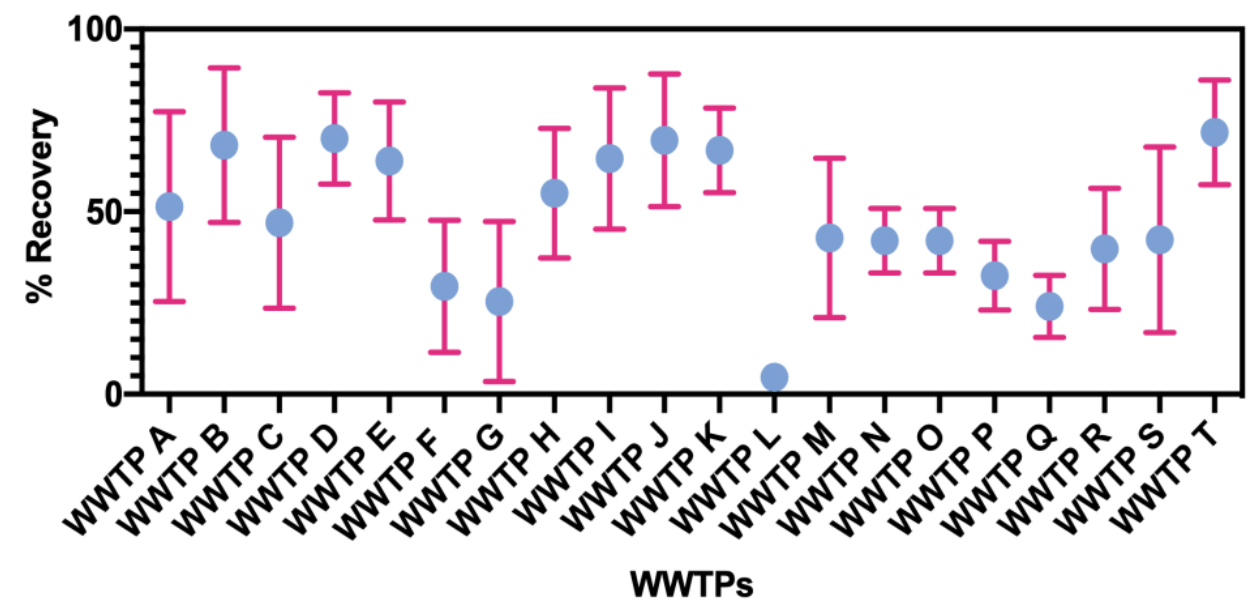

Fig. 5: Recovery of seeded murine hepatitis A virus (MHV) from 20 wastewater treatment plants (WWTPs) using a concentrating pipette Select ${ }^{\mathrm{TM}}$ (CP Select ${ }^{\mathrm{TM}}$ ). Each WWTP was sampled three times. Data source: CSIRO molecular microbiology laboratory, Queensland, Australia (unpublished data)

The sample volume is another important factor that may lead to different MLOD and falsenegative errors, especially when the concentration of the target viruses is relatively low in wastewater, as is the case for SARS-CoV-2 even in peak periods. Nevertheless, few studies have reported the ESV analysed using RT-PCR (i.e., considering both the volume of wastewater sampled and then the volume of the concentrated sample used in the analysis). In a comparison study of concentration methods for SARS-CoV-2, a bag-mediated filtration system (positive filtration) enabled the highest ESV $(15 \mathrm{~mL}$, concentrated from larger volume of wastewater), whereas up to $5.3 \mathrm{~mL}$ and $1.3 \mathrm{~mL}$ were assayed using ultrafiltration-based methods and PEG precipitation or skimmed milk flocculation (SMF) methods respectively (Philo et al., 2021).

Forés et al. (2021) reported similar ESV for Centricon ${ }^{\circledR}$ and concentrating pipette Select ${ }^{\mathrm{TM}}$ (CP Select ${ }^{\mathrm{TM}}$ ) ultrafiltration devices, resulting in concentration factors up to $333 \times$ and $250 \times$ respectively. Results in Fig. 6 show MLOD estimations based on three different procedures indicating that when low virus RNA concentrations are expected to occur in wastewater samples, the starting sample volume should be increased to avoid false-negative errors. However, the impacts of concentration method on recovery efficiency and RT-PCR inhibition should be evaluated when analyzing large volumes of wastewater. Gerrity et al. (2021) processed $10 \mathrm{~L}$ of wastewater for SARS-CoV-2 detection using a combined sample concentration approach with hollow fibre ultrafiltration (HFUF) followed by Centricon ${ }^{\circledR}$ centrifugal ultrafiltration. Despite achieving an ESV of $\sim 50 \mathrm{~mL}$ with this combined approach, virus recovery based on seeded bovine coronavirus dropped to $2 \%$. With HFUF or Centricon ${ }^{\circledR}$ alone, the ESV decreased to $\sim 1 \mathrm{~mL}$, but virus recovery increased to $>50 \%$. Therefore, when attempting to increase method sensitivity, one must simultaneously balance ESV and virus recovery, while also considering the practical aspects (e.g., time and cost) of sample collection and processing.

A method comparison study revealed a $7-\log _{10}$ range of recovery efficiency and ALOD values, demonstrating the broad range of outcomes possible with currently available protocols and highlighting the importance of characterizing performance prior to implementation (Pecson et al., 2021). That study did not necessarily indicate whether one approach was superior to another, but it did highlight the importance of method 
characterization, including potential trade-offs between sample concentration factor and virus recovery. That being said, extremely low ESVs and virus recoveries have a greater potential to yield false-negatives, or even artificially inflate adjusted concentrations.

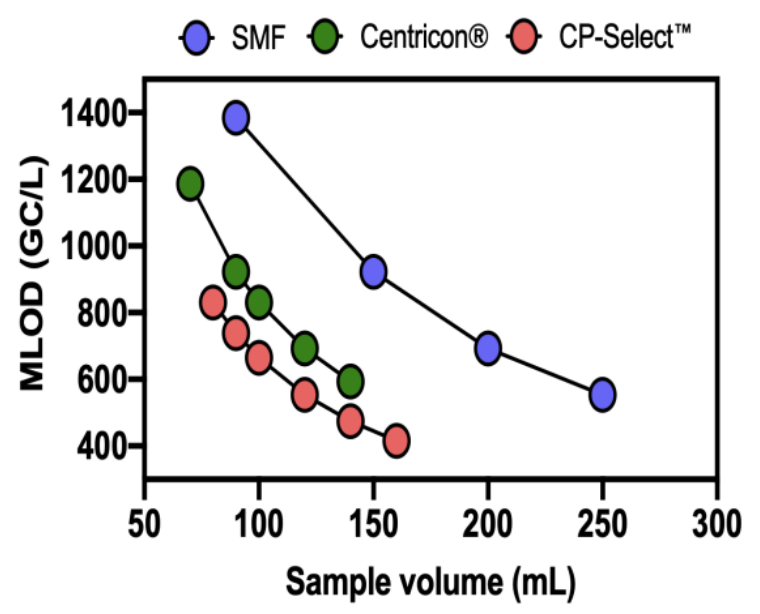

Fig. 6: Estimated method limit of detection (MLOD) according to the volume of sample processed, which was $300 \mu \mathrm{L}$ for the CP Select ${ }^{\mathrm{TM}}, 500 \mu \mathrm{L}$ for SMF and $240 \mu \mathrm{L}$ for Centricon ${ }^{\circledR}$. The MLOD was calculated assuming $323 \mathrm{GC}$ as the minimum number detected in RT-qPCR reaction using CDC N1 assay and a mean volume of sample concentrate for each concentration method. A 100\% recovery has been assumed for the entire concentration, RNA extraction and detection process. SMF: skimmed milk flocculation. Data obtained partially from Forés et al. (2021).

\subsection{RNA extraction}

Inefficient RNA extraction procedures can contribute to the occurrence of SARS-CoV-2 falsenegatives and little is known about which protocols are best for wastewater surveillance applications. Due to the COVID-19 pandemic, an overwhelming demand for materials and reagents for SAR-CoV-2 testing have resulted in manufacturer shortages, potentially requiring laboratories to modify method workflows to accommodate supply issues (Fomsgaard and Rosenstierne, 2020). In some cases, researchers have been forced to process samples using a range of alternative/uncommon RNA extraction kits, or to use methods lacking an RNA extraction step; all with varying levels of success (Fomsgaard and Rosenstierne, 2020; Merindol et al., 2020; Torii et al., 2020; Wee et al., 2020). Commercially available RNA extraction kits can vary in their efficiency and consistency in isolating viral RNA as well as efficacy in removing PCR inhibitors, even when sourced from the same supplier (Iker et al., 2013; Griffin et al., 2014; Zhang et al., 2018). Pivoting to alternative methodologies combined with potential inconsistencies in RNA recovery, even from commercial kits, the RNA extraction step remains a potential risk for false-negative detections. Furthermore, with indications of the emergence of SARS-CoV-2 variants around the world, confounded by delays in vaccine distribution, manufacturer shortages of these critical reagents will likely remain an issue for future wastewater surveillance efforts.

\subsection{RT-PCR amplification inhibition}

Municipal wastewater is a complex mixture of substances beyond fecal waste, including pharmaceuticals, personal care products, stormwater, sediments, household detergents, industrial effluents, metals and other substances. Some of these substances may completely 
or partially inhibit the RT-PCR amplification process leading to a false-negative result. These substances are generally referred to as PCR inhibitors and include a heterogeneous and poorly defined group of chemical substances known to inhibit PCR-based methods, including multi-ringed polysaccharides (e.g., humic and fulvic acids), fats, proteins, metal ions (e.g., iron and aluminium), RNases, and others (Schrader et al. 2021). There are multiple mechanisms of amplification inhibition including co-precipitation of inhibitors with nucleic acids either degrading or sequestering target nucleic acids; binding of some inhibitors to nucleic acid or enzymes, inhibiting polymerase activity; or chelating metal ions (i.e., $\mathrm{Mg}^{2+}$ ) necessary for optimal amplification performance. A full description of known mechanisms is reviewed in Schrader and colleagues (2012). For SARS-CoV-2 cDNA amplification, it has been demonstrated that the presence of such inhibitors can lead to false-negative errors in SARS-CoV-2 assays, especially when viral concentrations are low (D'Aoust et al., 2021; Gonzalez et al., 2020; Graham et al., 2021).

\subsection{RT-PCR assay selection}

The SARS-CoV-2 RNA genome offers multiple possible targets for RT-PCR assays including the nucleocapsid $(N)$, envelope protein ( $E)$, RNA dependent RNA polymerase (RdRP), open reading frame (ORF), membrane protein (M), and surface protein (S) genes. Multiple assays have been developed for each genetic region (Li et al., 2020). Relatively poor assay performance could lead to false-negative results. For example, a recent study by Vogels et al. (2020) compared the performance of nine primer-probe combinations targeting several genes (i.e., E, N, ORF1, RdRp) recommended by the World Health Organization (e.g., those developed by the Chinese Center for Disease Control and Prevention (China CDC), US CDC, Charité Institute of Virology, Universitätsmedizin Berlin (Charité) (Corman et al., 2020), and Hong Kong University (HKU) (Chu et al., 2020). This comparison was performed with standard reference materials and clinical samples (e.g., nasopharyngeal swabs, saliva, urine, and rectal swabs) seeded with the reference material. The authors demonstrated that at low viral concentrations ( 1 to 10 viral RNA copies/ $\mu \mathrm{L}$ ), not all assays yielded positive results suggesting that some assays may be more prone to false-negative errors than others (Vogels et al., 2020). Most notably, the RdRp reverse primer had mismatches with the reference material that were attributed to evolution of the virus, causing low analytical sensitivity

These assays were developed for clinical testing and many performed well with clinical samples, however, few studies have evaluated their performance for wastewater analyses. This is crucial given that wastewater is enriched in other viruses and pathogens. A recent study reports that genes are transcribed by cells infected by SARS-CoV-2 at different rates, suggesting that assays targeting the $\mathrm{N}$ gene could help reduce the incidence of falsenegatives (Kim et al., 2020). The US CDC N1 assay also outperformed the Charite assay and assays targeting the $\mathrm{M}$ gene and IP2/IP4 (RdRP) regions when applied to quantification of SARS-CoV-2 from wastewater in Spain (Perez-Cataluna et al., 2021). In another study, the US CDC N1 assay resulted in a longer period of positive detections in wastewater compared to IP2 and IP4, the E genome regions, while the US CDC N2 assay provided inconsistent results (Chavarria-Miro et al., 2021).

Fig. 7 depicts an experiment using the Australian National Measurements Institute (NMI) SARS-CoV-2 reference materials (https://www.industry.gov.au/news/new-australianstandard-helps-covid-19-hotspot-detection) indicating the differences in assay performance based on paired testing of wastewater dilutions with the CDC N1 and N2 assays. Finally, a study conducted in Germany reported increased sensitivity and specificity of IP2/IP4 (RdRP) and $\mathrm{M}$ gene targets compared to $\mathrm{N}$ gene and $\mathrm{E}$ gene assays (Westhaus et al., 2020), but cautioned that these assays might detect other endemic human coronaviruses, potentially inflating reported performance metrics. Although no study to date has conducted a head-tohead comparison of all SARS-CoV-2 assays in wastewater samples, however, the limited information available clearly indicates that some assays may be more suitable than others. 


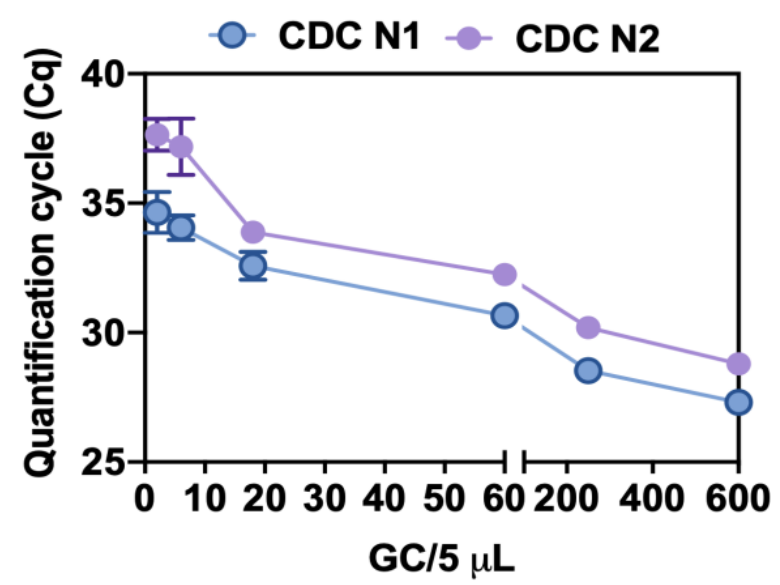

Fig. 7: Quantitation cycle $(\mathrm{Cq})$ values of the US CDC N1 and N2 RT-PCR assays determined using Australian National Measurement Institute (NMI's) SARS-CoV-2 calibrant comprised of six gravimetric dilutions at $600,245,60,18.5,6.5$, and $2 \mathrm{GC} / 5 \mu \mathrm{L}$ of RNA. The Bio-Rad CFX96 platform was used for RT-PCR amplification of N1 and N2 assays. Data source: CSIRO molecular microbiology laboratory, Queensland, Australia (unpublished data)

\subsection{RT-PCR assay performance characteristics}

PCR performance characteristics, such as sensitivity or assay limit of detection or quantification (ALOD or ALOQ), calibration model parameters for RT-qPCR (amplification efficiency, slope, Y-intercept) and dynamic range play an important role in interpreting the assay robustness and reproducibility, thus minimizing the potential for ambiguous results and detection failure (Bustin et al., 2009; Johnson et al., 2014). ALOD is the concentration of a target that can be detected with $95 \%$ probability (at least $95 \%$ of samples containing that quantity of target will be positive) (Bustin et al., 2009). ALOQ for RT-QPCR can be defined in several ways, but in general it depends upon the standard deviation around the lower concentrations of the standard curve. A relatively common practice is to establish the ALOQ based on the coefficient of variation (CV) for measurements of analytical standards near the limit of detection. Acceptable CV levels are generally 10 to 35\% (Forootan et al., 2017; Haugland et al., 2016). For example, an assay in which the $100 \mathrm{GC}$ standard has a CV of $15 \%$, and the $10 \mathrm{GC}$ standard has a CV of $75 \%$ would have a limit of quantification of 100 GC.

PCR-based assays with low ALOD and a wide dynamic range are ideal for wastewater surveillance applications. MLOD is the method sensitivity or a concentration of a target that can be detected consistently after incorporating loss through the entire process from sample concentration to extraction, while the method limit of quantification (MLOQ) is the concentration of a target that can be quantified with an acceptable level of precision when present in a sample. These values are calculated from the analytical limit of detection (ALOD) or quantification (ALOQ).

\subsection{Mutations in the RT-PCR target regions}

SARS-CoV-2 RNA can undergo strong selection pressures or high mutation rates or a combination of both, and this has resulted in the formation of several prominent genetic variants since late 2020 ( $\mathrm{Li}$ et al., 2020). Changes in key SARS-CoV-2 loci could result in reduced RT-PCR performance, which could lead to false-negative results depending on the location of the mutation relative to primers and probe target regions. The rate of genetic change varies across the SARS-CoV-2 genome, with structural domains (i.e., spike, membrane, envelope, and nucleocapsid proteins) generally undergoing stronger selection pressure (due to host immunity) resulting in the accumulation of more mutations compared to 
the non-structural genes (i.e., ORF1a and 1b) (https://virological.org). One pertinent example is the emergence of the B.1.1.7 lineage (https://virological.org). However, accumulation of mutations within the probe and/or primer target regions as the most of concern for wastewater surveillance as these could, over time, lead to a decrease in sensitivity of RT-PCR detection, and an increased rate of false-negative errors. For example, a recent report indicated that single nucleotide polymorphism (SNP) in the nucleoprotein (N) gene interfered with some SARS-CoV-2 RT-PCR assays in clinical testing but not others (Ziegler et al., 2020). Another group reported failure of the RT-PCR assay targeting the E gene due to a SNP (Artesi et al., 2020).

\subsection{PCR platforms}

RT-PCR (both RT-qPCR and dPCR) has become a mainstream detection method of SARSCoV-2 RNA in wastewater (Barcelo, 2020). However, like all technologies, RT-PCR is not without limitations; in particular, the reliance on a standard curve for RT-qPCR quantification and issues with amplification inhibition can be problematic. In recent years, digital PCR (dPCR) has emerged as an attractive alternative for environmental applications as it offers absolute quantification without the need for a standard curve, and it may be more sensitive and less prone to inhibition (Cao et al., 2015). As applied to the detection of SARS-CoV-2, RT-dPCR has been reported to be superior to RT-qPCR for clinical specimens, including nasopharyngeal samples (Falzone et al., 2020; Liu et al., 2020; Suo et al., 2020) and plasma from infected patients (Tedim et al., 2021), as it was found to be more sensitive and accurate.

While there are abundant examples in the literature comparing the performance of both technologies on clinical samples, analogous data for more complex matrices like wastewater, which is the basis of wastewater surveillance, are severely limited. For example, a recent study documented the successful application of RT-dPCR technology to quantify SARS-CoV2 from municipal wastewater but offered no direct comparison with RT-qPCR (Gonzalez et al., 2020). Of note, the potential for inhibition was assessed through the addition of a hepatitis G RNA control, resulting in approximately $50 \%$ recovery of seeded material and suggesting that RT-dPCR may also be affected by interference from PCR inhibitors in wastewater. Another study reported potential inhibition of RT-dPCR as compared to RT-qPCR when applied to the quantification of SARS-CoV-2 from wastewater sludge samples (D'Aoust et al., 2020), but this inference was based on a higher frequency of target detection by the RTQPCR, rather than the recovery of an exogenous control.

A direct comparison between RT-qPCR and RT-dPCR applied to aircraft and cruise ship wastewater samples indicated minimal differences in SARS-CoV-2 detection levels with no inhibition observed with either approach. Authors concluded that potential differences in the frequency of detection of SARS-CoV-2 may be influenced to a greater extent by individual assay design rather than the detection technology (Ahmed et al., 2020f). Another research group performed a comparative study using both RT-ddPCR (droplet digital PCR) and RTqPCR molecular workflows for the quantification of the US CDC N2 gene in influent wastewater from several WWTPs (Fig. 8). RT-ddPCR was able to identify a positive signal at an earlier date, when SARS-CoV-2 levels were presumably lower, compared to RT-qPCR analyses. The capability for earlier detection was reinforced by a comparison between analytical sensitivity of the two methodologies. Analysis indicated that the ALOD for N2 using RT-ddPCR was 0.25 copies/reaction whereas the ALOD for RT-qPCR was much higher at a concentration 60.22 copies/reaction. While RT-ddPCR may be more sensitive than RT-qPCR for SARS-CoV-2 detection from wastewater, additional studies are needed to confirm these initial findings. Park et al. (2020) suggested relying on RT-ddPCR for quantification of reference materials and diagnosis in patients but utilizing RT-qPCR for analysis of wastewater samples. A potential limitation of $\mathrm{APCR}$ is the subjective setting of the threshold that distinguishes positive results from the noise. 


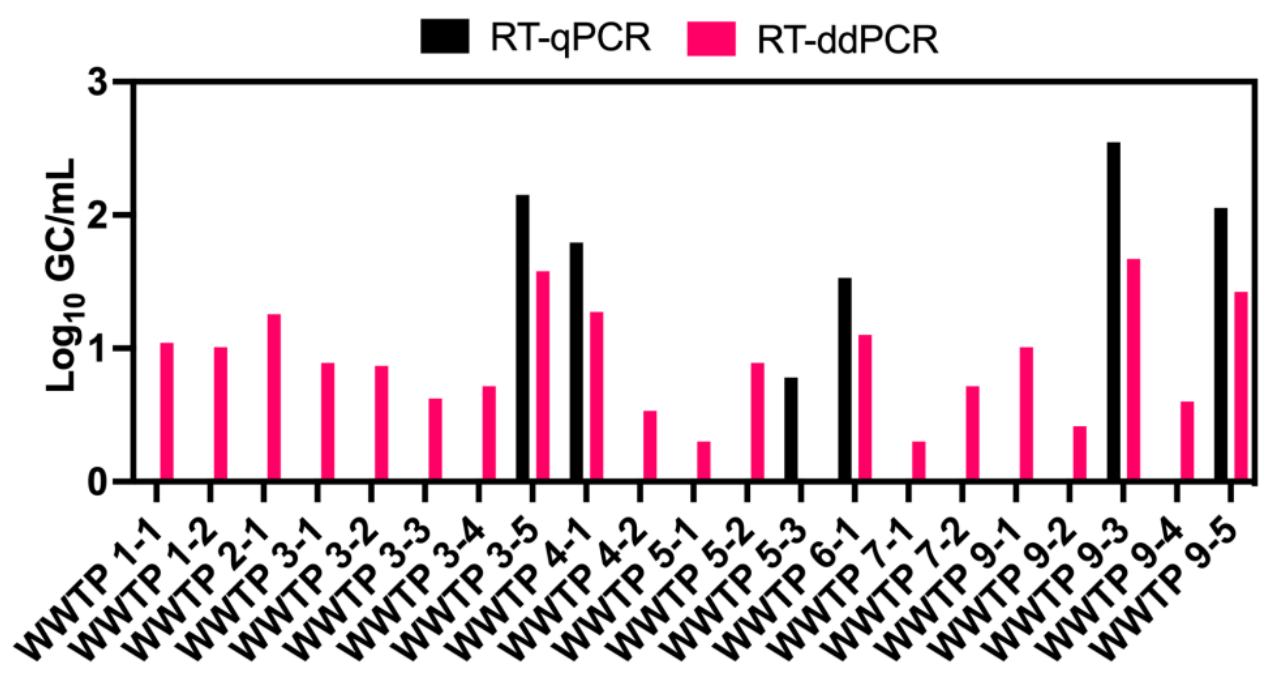

Fig. 8: SARS-CoV-2 (CDC N2) concentrations over time in gene copies $(\mathrm{GC}) / \mathrm{mL}$ from seven distinct wastewater treatment plants (WWTPs) servicing in south-east Virginia. The WWTPs serve catchment populations ranging between 69,509 to 343,016 individuals. Weekly sampling events began May 14, 2020 and continued through July 14, 2020. WWTPs are identified first by the arbitrary facility number followed by corresponding sample collection event (e.g., WWTP-5-3 would refer to third collection event for WWTP 5). Data obtained partially from Ciesielski et al. (2021).

\subsection{Number of replicates (sub-sampling error)}

Since the entire sample often cannot be analyzed, replicated subsamples may be used to detect or estimate the concentration of a target DNA/RNA present in a sample. Technical replicates test the variability of the analysis method and involve taking multiple subsamples from the same sample and analyzing each subsample. In contrast, biological or true matrix replicates test different independently obtained samples. In general, analysis of three biological replicates can provide robust results. However, even if three samples are obtained for RNA extraction in an environmental application, only a subsample (a portion) of the extracted material from each sample are used in a RT-PCR test. This sub-sampling practice has the potential to introduce error into RNA target measurements (Taylor et al., 2019). If a 1$\mu \mathrm{L}$ subsample of RNA is taken from a total volume of $100 \mu \mathrm{L}$ of RNA containing a total of 500 GC of SARS-CoV-2 RNA, the expected number of GC in $1 \mu \mathrm{L}$ of homogenous RNA subsample will be 5 . However, if the quantity of SARS-CoV-2 RNA is $50 \mathrm{GC}$ in a volume of $100 \mu \mathrm{L}$ RNA, the expected number of $\mathrm{GC}$ in the $1 \mu \mathrm{L}$ subsample will be 0.5 . Assuming a theoretical ALOD of $1 \mathrm{GC}$, the latter scenario has a $50 \%$ probability of a false-negative error, assuming a single RT-PCR reaction. Therefore, sub-sampling error is more pronounced in wastewater samples with low target concentrations.

It has been reported that subsampling error contributes to more than $10 \%$ of the variance when the concentration of a target in a subsample is below $100 \mathrm{GC}$, and above $30 \%$ when the concentration is below $10 \mathrm{GC}$. Technical variability of RT-qPCR assay results is reported to increase when yielding $\mathrm{Cq}$ values above 30 due to stochastic amplification, measurement uncertainty, and subsampling error (Taylor et al., 2019). Fig. 9 shows the detection rate of SARS-CoV-2 using the N1 assay in 523 wastewater samples in Queensland, Australia. Inclusion of six rather than three technical replicates resulted in a $5.4 \%$ detection frequency increase suggesting that sub-sampling error can contribute to false-negative errors. 


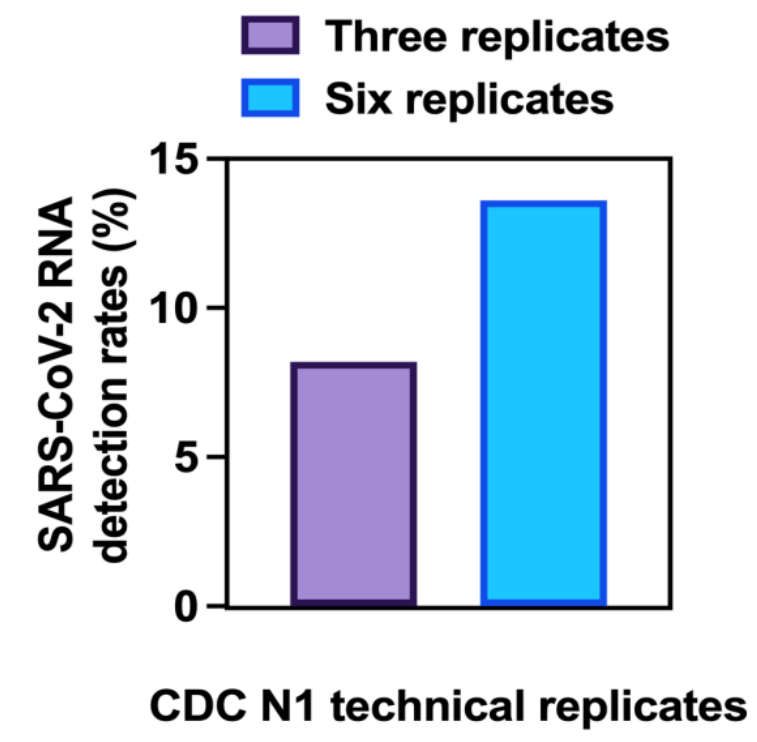

Fig. 9: Detection rate of SARS-CoV-2 using the US CDC N1 assay in $n=523$ wastewater samples. The detection rate using six $\mathrm{N} 1$ replicates is compared with a hypothetical detection rate where three $\mathrm{N} 1$ replicates were used. This assumes that a detection of one $\mathrm{N} 1$ replicate when six replicates were used is equivalent to 0.5 of a detection when three replicates were used (i.e., assumes that results of PCR technical replicates are independent of each other). Data source: CSIRO molecular microbiology laboratory, Queensland, Australia (unpublished data).

\subsection{Data reporting}

Data reporting practices merit special consideration for highly infectious and transmissible viruses (and other biological agents) such as SARS-CoV-2 that present serious threats to global public health. For example, in instances where it has been documented that a RT-PCR detection is not a result of extraneous contamination (i.e., false-positive), reporting detections below an established ALOQ such as detectable but not quantifiable (DNQ) (Layton et al., 2013) reporting may be acceptable. In this case, results below assay ALOQ/MLOQ are classified as positive therefore increasing the sensitivity of the assay and reducing the incidence of false-negative results. However, the SARS-CoV-2 wastewater surveillance dashboard in Finland denotes such results as inconclusive to avoid the implications of potential false-negative errors while emphasizing the importance of measures to avoid falsepositive errors (Supplementary Fig. 3). Another important factor in data reporting is the lack of useful information in published articles regarding sample processing workflow. Such information is crucial in terms of understanding the potential for false-negative and -positive errors. For example, the absence of clear definitions for a detect and non-detect can makes it more challenging to assess the potential impact of both false-positive and -negative errors. Without information regarding the laboratory workflow, it is difficult to determine whether a sub-optimal result was due to sampling, poor virus concentration and/or RNA extraction efficiency, or use of a less sensitive RT-PCR assay, or other factors. 


\section{Implications of SARS-CoV-2 false-positive and -negative errors}

When a wastewater surveillance program reports a positive result to public health units, they may immediately contact and advise public health agencies and/or community leaders on the location. Local public health units may seek further wastewater testing to confirm presence of SARS-CoV-2 before actions commence, or they may initiate targeted sampling/testing of localized human populations (i.e., upstream within the sewer systems). Confirmed positive detections lead to public announcements by government agencies, journalists and others revealing that SARS-CoV-2 was detected in wastewater. They may also a larger segment of the population to seek testing for COVID-19 if they live within or have visited the area, and particularly if they have any COVID-19 symptoms. If community-wide clinical surveillance in response to positive wastewater results subsequently fails to identify active infections, the presumed wastewater surveillance false-positive error may cause policymakers, public health officials, and the public to lose confidence in wastewater surveillance and question its reliability as an early warning system or useful information tool.

Conversely, it is possible for COVID-19 infections to be present in the community, and for SARS-CoV-2 RNA to be present in wastewater samples, and yet wastewater sample testing yields negative results (RT-PCR and wastewater surveillance false-negative). Such wastewater surveillance false-negative errors can be just as problematic as false-positive errors. By failing to alert public health officials to a potential outbreak or by generally underestimating the extent to which SARS-CoV-2 is circulating in a community, wastewater surveillance false-negative errors may put communities and healthcare workers at unnecessary risk by providing a false sense of security. Such false-negative errors in the absence of clinical testing may result in an increase in community transmission before any control measures can be put in place, with a concomitant rise in hospital admissions. This may in turn prompt more severe mitigation measures and the economy than if an outbreak had been caught earlier through wastewater surveillance results.

In many communities the results of SARS-CoV-2 RT-PCR wastewater analyses are published on social media, internet dashboards, and/or in the media (Wastewater surveillance program results | Health and wellbeing | Queensland Government (www.qld.gov.au). Falsenegative errors may suggest to the public that SARS-CoV-2 infections are declining or absent in the community, which could result in greater public apathy and resultant disregard of public health mitigation measures. In addition, reporting of false-negative errors, once discovered, may reduce public confidence in wastewater surveillance. In some jurisdictions, there may also be legal consequences to reporting inaccurate results. This has not yet become apparent in practice, however, should be considered where SARS-CoV-2 RT-PCR screening of wastewater is offered as a service by commercial laboratories.

\section{Strategies to identify and mitigate SARS-CoV-2 false-positive and false-negative errors}

To characterize and mitigate SARS-CoV-2 false-positive and false-negative errors, we recommend consulting the well-established MIQE guidelines which address data reporting for steps ranging from experimental design to data analysis (Bustin et al., 2009; Huggett et al., 2013). Nevertheless, such guidelines may need to be adapted to overcome challenges posed specifically by environmental surveillance or monitoring of pathogens including SARS-CoV-2 wastewater surveillance.

\subsection{Practices to identify and minimize false-positive errors}

Contamination of an RT-PCR assay from extraneous sources of nucleic acid is a major source of false-positive errors. Nucleic acid from equipment, other samples, and previously synthesized amplicons can contaminate samples or reagents. This section highlights key 
strategies for identifying and minimizing false-positive errors in wastewater surveillance applications.

\subsubsection{Laboratory organization, management, and workflow}

Laboratory organization, management, workflow and QA/QC practices can help minimize the rate of false-positive errors in wastewater surveillance. Thorough cleaning of laboratory work areas with methods proven to destroy or disintegrate RNA on a routine basis (e.g., bleach and UV) is necessary (Huggett et al., 2020). It is also important to physically separate key steps in the RT-PCR methodology creating autonomous work areas for sample processing (e.g., pre-treatment and concentration of samples), RNA extraction, RT-PCR master mix setup (i.e., clean room), amplification, and post-RT-PCR (i.e., gel electrophoresis, sequencing, etc.). Each designated work area should be equipped with dedicated equipment, consumables, and personal protective equipment. Furthermore, cross-contamination between dedicated areas can be eliminated by implementing a unidirectional laboratory workflow practice (Millar et al., 2002; Huggett et al., 2020).

\subsubsection{Identification of contamination from field and laboratory environments}

Controls should be used to ensure that contamination does not confound results. Contamination during sample collection can be identified by including a field blank (USEPA, 2014). A field blank is performed by dispensing a sample of sterile water into a sample container in the field, which is subsequently transported to the analytical laboratory together with the collected wastewater samples (USEPA, 2002; Esbensen and Ramsey, 2015). An equipment blank control entails decanting a sample of laboratory grade water over or through the sampling equipment, prior to the collection of a wastewater sample (Esbensen and Ramsey, 2015). In contrast, a transport blank is a sample of sterile water that is transported from the laboratory to the sampling site, whereafter it is transported back to the laboratory without having been exposed to the sampling environment. The transport blank thus serves to verify that contamination was not introduced due to travel conditions.

A method blank should always be included with each batch of wastewater samples tested to ascertain whether contamination was introduced in the laboratory during sample analysis (USEPA, 2014). The method blank should be analyzed in parallel with the wastewater samples using the exact same procedure. For the RT-PCR amplification step(s), multiple NTC tests (minimum of three) should be included with each thermal cycling instrument run. A reverse transcription NTC should also be included for two-step RT-PCR applications to identify whether complementary DNA (cDNA) or SARS-CoV-2 RNA is the source of contamination. It can also be helpful to watch for any patterns in the occurrence of falsepositives based on the RT-PCR experiment design, when interpreting results near or below a defined RT-PCR ALOD or ALOQ. Unexpected patterns in contamination detection based on experimental set-up or proximity to samples with high concentration of the target or reference materials can suggest sample cross-contamination (Huggett et al., 2020). Finally, if falsepositives are observed in control reactions, it may be useful to sequence these samples to confirm that they are SARS-CoV-2 genetic markers.

\subsubsection{Minimize sample handling prior to concentration}

From the time a wastewater sample is collected from a sewer system to sample concentration, it is vital to minimize contact with any materials or aerosols from the field and laboratory environments. The use of probes or any other materials that come into contact with a sample can provide the opportunity to introduce contamination due to improper cleaning and/or exposure to aerosols. Wastewater samples should be immediately sealed and only opened during composite preparation, aliquoting, and concentration steps. Practices that reduce the amount of time that samples are exposed to aerosols in the field and laboratory environment are recommended. In addition, it is also important to avoid the insertion of any 
instrument probes into a sample to take measurements such as temperature or turbidity. Instead, take measurements on a split sample after adequate homogenization and aliquoting.

\subsubsection{Reagent screening and handling}

The integrity of new batches of SARS-CoV-2 RT-PCR reagents (i.e., primers, probes, PCR master mix, and DNase/RNase free water) should be confirmed before use (Bustin et al., 2020; Huggett et al., 2020). This can be achieved by analyzing 10 to 12 NTC replicates alongside a positive control for each new lot of RT-PCR reagents. Moreover, the required amounts of RT-PCR master mix, primer-probe mix, and nuclease-free water should preferably be aliquoted for a single use in order to reduce potential contamination associated with the frequent use of stock solutions over a prolonged time period.

\subsubsection{Plan a course of action}

SARS-CoV-2 surveillance programs should consider developing a contingency plan to minimize interruptions in laboratory workflow to mitigate contamination. While contamination response plans will likely vary by wastewater surveillance program, there are multiple practices that should be considered when false-positive errors occur (Table 1). When a falsepositive is observed, it is important to confirm by gel-electrophoresis and sequencing. It is also necessary to carefully consider which controls are yielding contamination. For example, if field and method blanks are negative, but the RT-PCR NTC tests identify contamination, then troubleshooting should focus on the amplification work area and methodologies. In addition to verifying the presence of a SARS-CoV-2 false-positive and the responsible RTPCR method step, it is necessary to expunge the contaminated reagent or equipment from the sample testing environment.

All unsealed sample collection and laboratory testing materials and reagents used throughout the entire analysis should be discarded. All work area surfaces (e.g., bench tops, floors, etc.) and laboratory equipment (e.g., microcentrifuges, microtube racks, etc.) should be treated with methods proven to degrade nucleic acids. Hydrogen peroxide or ethylene oxide (McEvoy and Rowan, 2019) gas sterilization may be necessary for pipettes and other equipment with working surfaces that are not amendable to surface cleaning. After all work areas and equipment are cleaned, it may be advisable to further confirm that the contamination source has been removed and implement additional practices to prevent the reoccurrence of contamination.

Practices will vary by the source of false-positives, for example, using the NTC contamination example above, it may be useful to use an RT-PCR master mix formulation that includes a deoxynucleotide mix containing uracil instead of thymine along with a heatlabile uracil-N-glycosylase (UNG), which can be used to minimize potential carryover amplification contamination during the RT-PCR amplification of SARS-CoV-2 (Blanchard et al., 2014; Mascuch et al., 2020). For other sources of contamination, it may be advantageous to seek additional analyst training or to implement additional control measures such as an equipment or transport blanks. Finally, it is crucial to demonstrate the absence of contamination leading to false-positive errors by systematically testing field blanks, method blanks, and NTC tests before returning to wastewater sample testing.

Table 1: Key elements of a successful false-positive mitigation plan

\begin{tabular}{|c|l|}
\hline \multicolumn{1}{|c|}{ Element } & \multicolumn{1}{c|}{ Corrective Actions } \\
\hline Verify source of false-positive(s) & $\begin{array}{l}\text { Confirm SARS-CoV-2 genetic marker(s) via gel- } \\
\text { electrophoresis and/or sequencing } \\
\text { Use appropriate controls (e.g., field, method, no-template) to } \\
\text { identify sample collection, processing, or }\end{array}$ \\
\hline
\end{tabular}




\begin{tabular}{|l|l|}
\hline & RT-PCR method step(s) where contaminant(s) introduced \\
\hline \multirow{5}{*}{$\begin{array}{l}\text { Expunge contamination from test } \\
\text { environment }\end{array}$} & $\begin{array}{l}\text { Discard all unsealed consumables and reagents throughout } \\
\text { entire method }\end{array}$ \\
\cline { 2 - 2 } & $\begin{array}{l}\text { Use aseptic technique and properly disinfect/sterilize all } \\
\text { sample collection equipment, devices, bottles, and other } \\
\text { laboratory consumables }\end{array}$ \\
\cline { 2 - 2 } & Thoroughly clean all work area surfaces and equipment \\
\hline \multirow{5}{*}{$\begin{array}{l}\text { RT-PCR method updates } \\
\text { (varies by source) }\end{array}$} & $\begin{array}{l}\text { Strict enforcement of unidirectional laboratory workflow and } \\
\text { dedicated equipment practices }\end{array}$ \\
\cline { 2 - 2 } & $\begin{array}{l}\text { Implement additional contamination monitoring for } \\
\text { responsible step }\end{array}$ \\
\cline { 2 - 2 } & Use different reagent lot \\
\cline { 2 - 2 } & $\begin{array}{l}\text { Use customized reagents that minimize amplicon } \\
\text { amplification }\end{array}$ \\
\cline { 2 - 2 } & Additional analyst training \\
\hline Demonstrate absence of & $\begin{array}{l}\text { Use appropriate controls (e.g., field, method, no template) to } \\
\text { verify contamination has been eliminated }\end{array}$ \\
\hline
\end{tabular}

\subsection{Practices to minimize false-negative errors}

A broad range of challenges associated with very different factors can contribute to falsenegative errors in wastewater surveillance for SARS-CoV-2, including sampling strategy, variability in community shedding and sewage composition, non-representative sampling, improper sample handling, lack of laboratory analyst proficiency, and interferences originating from the wastewater sample itself. This section describes practices and potential strategies to identify and minimize the occurrence of false-negative errors in SARS-CoV-2 RT-PCR testing.

\subsubsection{Sample handling}

Practices that limit exposure to suboptimal temperatures during transport and storage prior to concentration and RNA extraction are recommended. Temperature monitoring systems such as iButton (iButtonLink, Whitewater, WI, USA) can be included during transport to ensure samples are not subject to rapid or long-term fluctuations in temperature, that make them more susceptible to RNA breakdown. This is particularly crucial when sample transportation occurs over multiple days or under extreme temperature conditions. To minimize RNA degradation, samples should be cooled and stored at $4^{\circ} \mathrm{C}$, shipped as quickly as feasible, and processed within 48-72 $\mathrm{h}$ after collection (Tan et al., 2018).

Storing bulk wastewater samples at $-20^{\circ} \mathrm{C}$ and $-80^{\circ} \mathrm{C}$ should be avoided due to potential damage due to freezing and thawing (Calcott, 1978). However, concentrated samples that are concentrated on filters or that are otherwise ready for direct analysis (i.e., ultrafiltered samples) can be stored at $-20^{\circ} \mathrm{C}$ and $-80^{\circ} \mathrm{C}$ for longer periods of time (Salehi and Najafi, 2014), especially if stabilized in a storage buffer (i.e., guanidinium thiocyanate). RNA extracts can be stored at $-20^{\circ} \mathrm{C}$ or $-80^{\circ} \mathrm{C}$, but multiple freeze thaws should be avoided. In addition, it is ideal to avoid wastewater sample pasteurization, if possible, because there is currently conflicting information on its effect on SARS-CoV-2 detection. While heat treatment may be necessary to ensure the safety of analysts in sub-optimal laboratory conditions, this high temperature treatment may reduce the ability to detect trace quantities of SARS-CoV-2.

\subsubsection{Sampling strategies}

Numerous factors can influence the concentration of SARS-CoV-2 in a wastewater sample, ranging from infection rates to individual fecal shedding trends, to the location in the wastewater collection/treatment system where samples are collected. It is therefore important to know and collect as much metadata as possible about the local wastewater system (e.g., relevant COVID-19 public health data from the local community, wastewater flow rate, pre- 
treatment steps such as chlorination or coagulant addition) to minimize or at least characterize the risk of false-negatives for wastewater surveillance applications. Information on peak use times, impact of local precipitation (e.g., storm events, snow melts, etc.), and land use in service areas (i.e., residential vs. commercial vs. industrial) can be useful to customize wastewater sampling to maximize the likelihood of detecting SARS-CoV-2 in a community. For example, if a local wastewater facility service area includes industrial and residential sectors, it may be strategic to collect samples from a pump station associated with residential areas rather than collecting a WWTP influent sample that contains mixed industrial and residential wastewater.

In many situations, composite sampling could help minimize false-negatives due to fluctuations in sewage composition over time. This is particularly important to detect shedding from a very few individuals. A flow-weighted composite sample is highly recommended as it accounts for the fluctuations in flow at the influent of a WWTP. If this is not possible, timeweighted composite sample should be the second choice. It may be necessary to conduct pilot experiments to optimize time intervals and/or flow conditions for optimal composite sampling. If only grab samples are collected in the absence of autosamplers or lack of logistics, sampling should occur during times when SARS-CoV-2 loads are expected to be high. It might also be useful to consider collecting multiple grab samples over a short duration (3-4 h) or deploy passive samplers to increase the probability of detecting SARS-CoV-2, especially in areas with low infection rates. In the event of precipitation, larger volumes of wastewater may need to be sampled to compensate for the dilution factor. Analyzing a larger volume (i.e., 1-2 L) will also increase detection sensitivity when COVID-19 cases are low or absent, assuming there is not a corresponding reduction in virus recovery during sample concentration. Primary sludge may be an attractive alternative to untreated wastewater because of solid particles that contain a wide array of enteric viruses (Peccia et al. 2020). However, the occurrence of SARS-CoV-2 in primary sludge need to be further characterized.

\subsubsection{Virus concentration and RNA extraction}

Any laboratory involved in or intending to participate in wastewater surveillance of SARSCoV-2 should identify viable long-term options and evaluate virus concentration and RNA extraction methods on the basis of performance and practical aspects (e.g., access to necessary equipment, labor, cost, and potential supply chain limitations) prior to implementation. SARS-CoV-2 should be concentrated from both liquid and solid phases of wastewater especially when small volume (i.e., $<100 \mathrm{~mL}$ ) of wastewater sample is processed in regions with low COVID-19 clinical cases.

Commercial RNA extraction kits often used in SARS-CoV-2 studies consist of silica columns specifically designed for efficient removal of polyphenolic compounds, humic/fulvic acids, tannins, and melanin (La Rosa et al., 2021; Graham et al., 2021), however, extractions based on nucleic acid solubility (precipitation) could be more effective in some scenarios. The performance of virus concentration and RNA extraction methods should be determined by seeding an appropriate sample process control in wastewater. If performance is not satisfactory in a series of samples, switching to alternative methods may reduce the likelihood of observing a false-negative due to poor virus concentration and RNA recovery. When possible, it is recommended that RNA recovery be monitored on a sample-specific basis, or at least routinely, due to potential shifts in wastewater composition over time.

\subsubsection{Inclusion of sample processing controls}

Systematic errors that introduce unwanted bias in SARS-CoV-2 measurements can lead to false-negative errors. Multiple studies reported substances commonly found in environmental samples that readily bind to nucleic acids and, when bound, force a shift in nucleic acid conformation (Cai et al., 2006). These interactions have been shown to interfere with nucleic acid recovery in surface waters polluted with wastewater and were undetectable with a 
molecular process control (Shanks et al., 2016). It is highly likely that this type of interference can occur in wastewater surveillance. To monitory for this potential source of false-negative errors, it is recommended to include a sample process control (i.e., a surrogate virus) to obtain sample-specific information about the recovery efficiency of the entire process or even a specific step within that methodology (Ahmed et al., 2020e; McMinn et al. 2021). A sample process control should be included for at least $10-20 \%$ of samples tested in a surveillance program. The biological and physical characteristics of the sample process control should be similar to SARS-CoV-2. In the absence of an appropriate surrogate, internal controls such as pepper mild mottle virus (Rosario et al., 2009) or crAssphage (Stachler et al., 2017) can also be used as an indicator of fecal strength or to monitor method performance.

\subsubsection{Monitoring for PCR inhibition}

Appropriate molecular process controls should be used to monitor for the presence of suboptimal assay performance (Hata et al., 2011) and must be included with every wastewater sample tested (Murray et al., 2013). Pecson et al. (2021) demonstrated that the RT-qPCR methods generally passed in terms of traditional inhibition controls, specifically seeding a molecular process control into a nucleic acid extract and assessing changes in $\mathrm{Cq}$ value. However, some samples still exhibited non-sigmoidal amplification curves that might indicate partial inhibition. Therefore, inhibition can present in multiple ways, by preventing amplification of the intended target or biasing amplification. If inhibitors are suspected, efforts should be taken to minimize inhibition to exclude false-negative errors. Multiple strategies exist for mitigating amplification inhibition in PCR-based experiments (Gibson et al., 2012).

In some cases, inhibition can be alleviated by utilizing a different RNA extraction approach capable of removing the specific inhibitor of concern. Others utilize inhibitor-tolerant designer polymerases such as Environmental Master Mix (Thermo Fisher Scientific, Grand Island, NY, USA), which has been shown to reduce the occurrence of amplification inhibition in environmental qPCR applications (Cao et al., 2012). Another widely applied approach is sample dilution (ISO15216-1:2017). While dilution testing is guaranteed to help alleviate inhibition, it also directly reduces the concentration of the genetic target, potentially leading to a false-negative result, and it is not useful when many samples are expected to provide a true-negative results. Therefore, sample dilution is not recommended, or should be limited (e.g., 2-fold vs. 10-fold), for trace applications such as the detection of low levels of SARSCoV-2 in wastewater.

\subsubsection{Assay optimisation and selection considerations}

RT-PCR assay protocols, such as those used for surveillance applications, should include optimized annealing temperatures and oligonucleotide concentrations (Bustin et al., 2009; Huggett et al., 2013). In addition, RT-PCR performance characteristics such as ALOD and ALOQ should be established using appropriate reference materials and following practices outlined in the MIQE guidelines (Bustin et al., 2009; Huggett et al., 2013; dMIQE Group and Huggett, 2020) prior to wastewater testing. Since the emergence of SARS-CoV-2, mutations and selection within the human population have led to new variants that are widespread in certain regions or worldwide (Peñarrubia et al., 2020). Although this phenomenon not yet led to significant issues with the molecular assays commonly used for SARS-CoV-2 detection and quantification, it is important to monitor the genomic properties of local SARS-CoV-2 populations on a routine basis and keep up to date on emerging lineages worldwide to allow for timely modification of primer and/or probe sequences to minimize detection biases and, in extreme cases, false-negatives.

\subsubsection{Optimizing experimental design for trace detection of a virus}

To reduce the damage of fragile RNA templates, freezing and thawing prior to testing should be avoided. Where possible, it is ideal to test samples immediately after RNA extraction (no 
freezing prior to RT-PCR amplification). Material may also be lost due to absorption to microtubes even when using low-retention plastics. If RNA extracts must be stored for prolonged periods of time prior to testing ( $>30$ days), stability should be verified to ensure no degradation has occurred potentially leading to a false-negative result (The dMIQE group and Hugget, 2020). A molecular processing control could be invaluable providing a reference with a known concentration to determine if the integrity of the RNA extract has significantly changed during storage. It can also be useful to increase the number of replicates tested to increase the probability of detecting a trace quantity. This practice is important not only for wastewater samples, but also for contamination controls (e.g., field blanks, method blanks, and no template controls). Increasing the sample volume may also be helpful as long as it does not result in reduced RNA recovery and/or a higher incidence of RT-PCR amplification inhibition. It is beneficial to specify ALOD, MLOD, ALOQ and MLOQ definitions. This allows for the unambiguous interpretation of trace detections in the absence of any evidence of contamination in control experiments. Finally, it is useful to confirm trace detections, at least a subset of samples, via sequencing.

\section{Conclusions}

Despite the challenges faced by researchers and agencies pursuing the rapid implementation of wastewater surveillance during a pandemic, SARS-CoV-2 surveillance has emerged as a powerful tool that can inform public health professionals about the presence of infections in a community. Such data, along with clinical testing results, make it a powerful and complementary tool for the assessment and management of COVID-19 in communities. Wastewater surveillance is a rapidly developing and growing area of research and is already playing an important role in this pandemic. Wastewater surveillance strategies will also be vital for preventing new outbreaks and managing future pandemics, as well as more traditional targets such as seasonal flu, enteric pathogens and antimicrobial-resistant bacteria and their genes. However, many wastewater analysis protocols are not optimized for trace analysis of viruses or other substances, making them susceptible to false-positive and falsenegative errors, as discussed in this review. It is important to acknowledge these challenges when interpreting data and inferring the probability that individuals in the community are infected. Improvements are needed for a reliable rapid detection application. To be able to detect SARS-CoV-2 or any other target of public health interest with greater accuracy, it is essential to set coordinated guidelines on sampling, establish stringent QA/QC practices, and identify effective concentration, efficient RNA extraction, and highly sensitive and specific RTPCR assays for detection. While standardization of some aspects of the laboratory workflow may not be appropriate or possible due to variability in methods, instruments and reagents, it is essential to seek broad inter-laboratory harmonization as much as possible. Additional research is also warranted including inter-laboratory studies utilizing a standardized reference material and protocols to better understand the variability associated with various aspects of the methods in use. In this way, under-performing laboratories could validate their performance against laboratories that demonstrated superior performance.

\section{Disclaimer}

The views expressed in this article are those of the author(s) and do not necessarily represent the views or policies of the U.S. Environmental Protection Agency. The U.S. Environmental Protection Agency through the Office of Research and Development provided technical direction but did not collect, generate, evaluate, or use the environmental data described herein. 


\section{References}

Ahmed, W., Harwood, V.J., Gyawali, P., Sidhu, J.P.S., Toze, S., 2015. Comparison of concentration methods for quantitative detection of sewage-associated viral markers in environmental waters. Appl. Environ. Microbiol. 81(6), 2042-2049.

Ahmed, W., Angel, N., Edson, J., Bibby, K., Bivins, A., Brien, J.W.O., Choi, P.M., Kitajima, M., Simpson, S.L., Li, J., Tscharke, B., Verhagen, R., Smith, W.J.M., Zaugg, J., Dierens, L., Hugenholtz, P., Thomas, K. V, Mueller, J.F., 2020a. First confirmed detection of SARS-CoV-2 in untreated wastewater in Australia: A proof of concept for the wastewater surveillance of COVID-19 in the community. Sci. Total Environ. 728, 138764.

Ahmed, W., Tscharke, B., Bertsch, P.M., Bibby K, Bivins, A., Choi, P., Clarke, L., Dwyer, J., Edson, J., Nguyen, T.M.H., Brien, J.W.O., Simpson, S.L., Sherman, P., Thomas, K.V., Verhagen R., Zaugg, Z., Mueller, J.F., 2020b. SARS-CoV-2 RNA monitoring in wastewater as a potential early warning system for COVID-19 transmission in the community. Sci. Total Environ. 761,144216.

Ahmed, W., Bertsch, P.M., Bibby, K., Haramoto, E., Hewitt, J., Huygens, F., Gyawali, P., Korajkic, A., Riddell, S., Sherchan, S.P., Simpson, S.L., Sirikanchana, K., Symonds, E.M., Verhagen, R., Vasan, S.S., Kitajima, M., Bivins, A., 2020c. Decay of SARS-CoV-2 and surrogate murine hepatitis virus RNA in untreated wastewater to inform application in wastewater-based epidemiology. Environ. Res. 191, 110092.

Ahmed, W., Bivins, A., Bertsch, P.M., Bibby, K., Choi, P.M., Farkas, K., Gyawali, P., Hamilton, K.A., Haramoto, E., Kitajima, M., Simpson, S.L., Tandukar, S., Thomas, K.V., Mueller, J.F., 2020d. Surveillance of SARS-CoV-2 RNA in wastewater: methods optimization and quality control are crucial for generating reliable public health information. Curr. Opin. Environ. Sci. Health. 17, 82-93.

Ahmed, W., Bertsch, P.M., Bivins, A., Bibby, K., Farkas, K., Gathercole, A., Haramoto, E., Gyawali, P., Korajkic, A., McMinn, B.R., Mueller, J.F., Simpson, S.L., Smith, W.J.M., Symonds, E.M., Thomas, K.V., Verhagen, R., Kitajima, M., 2020e. Comparison of virus concentration methods for the RTqPCR based recovery of murine hepatitis virus, a surrogate for SARS-CoV-2 from untreated wastewater. Sci. Total Environ. 739, 139960.

Ahmed, W., Bertsch, P.M., Angel, N., Bibby, K., Bivins, A., Dierens, L., Edson, J., Ehret, J., Gyawali, P., Hamilton, K.A., Hosegood, I., Hugenholtz, P., Jiang, G., Kitajima, M., Sichani, H.T., Shi, J., Shimko, K.M., Simpson, S.L., Smith W.J.M., Symonds, E.M., Thomas, K.V., Verhagen, R., Zaugg, J., Mueller, J.F., 2020f. Detection of SARS-CoV-2 RNA in commercial passenger aircraft and cruise ship wastewater: a surveillance tool for assessing the presence of COVID-19 infected travellers. J. Trav. Med. 27(5), taaa116.

Albano, P.M., Notarte, K.I., Macaranas, I., Maralit, B., 2020. Cross-contamination in molecular diagnostic laboratories in low- and middle-income countries: A challenge to COVID-19 testing. Philipp. J. Pathol. 5, 1-5.

Albastaki, A., Naji, M., Lootah, R., Almeheiri, R, Almulla, H., Almarri, I., Alreyami, A., Aden, A., Alghafri, R., 2021. Sci. Total Environ. 760, 143350. First confirmed detection of SARSCoV-2 in untreated municipal and aircraft wastewater in Dubai, UAE: the use of wastewater-based epidemiology as an early warning tool to monitor the prevalence of COVID-19. Sci. Total Environ. 760, 143350.

Alleman, M.M., Rey-Benito, G., Burns, C.C., Vega, E., 2021. Environmental surveillance for poliovirus in Haiti (2017-2019): The dynamic process for the establishment and monitoring of sampling sites. Viruses. 13(3), 505.

Artesi M., Bontems, S., Göbbles, P., Franckh, M., Maes, P., Boreux, R., Meex, C., Melin, P., Hayette, M.P., Bours, V., Durkin, K.J., 2020. A recurrent mutation at the position 26340 of SARS-CoV-2 is associated with failure of the $E$ gene quantitative reverse transcriptionPCR utilized in a commercial dual-target diagnostic assay. Clin. Microbiol. 58(10), e01598-20.

Asghar, H., Diop, O.M., Weldegebriel, G., Malik, F., Shetty, S., El Bassioni, L., Akande A.O., Al Maamoun, E., Zaidi, S., Adeniji, A.J., Burns, C.C., Deshpande, J., Oberste, M.S., Lowther, S.A., 2014. Environmental surveillance for polioviruses in the Global Polio Eradication Initiative. J Infect Dis. 1(210 Suppl 1), S294-303.

Australian Department of Health 2021. Coronavirus (COVID-19) current situation and case numbers. https://www.health.gov.au/news/health-alerts/novel-coronavirus-2019-ncov- 
health-alert/coronavirus-covid-19-current-situation-and-case-numbers\#covid19-summarystatistics.

Aymerich, I., Acuña, V., Ort, C., Rodríguez-Roda, I., Corominas, L., 2017. Fate of organic microcontaminants in wastewater treatment and river systems: An uncertainty assessment in view of sampling strategy, and compound consumption rate and degradability, Water Res. 520,152-161.

Barcelo, D., 2020. Wastewater-based epidemiology to monitor COVID-19 outbreak: present and future diagnostic methods to be in your radar. Case Studies Chem. Environ. Eng. 2, 100042.

Barril, P.A., Pianciola, L.A., Mazzeo, M., Ousset, M.J., Jaureguiberry, M.V., Alessandrello, M., Sánchez, G., Oteiza, J.M., 2021. Evaluation of viral concentration methods for SARSCoV-2 recovery from wastewaters. Sci Total Environ. 756, 144105.

Bivins, A., North, D., Ahmad, A., Ahmed, W., Alm, E., Been, F., Bhattacharya, P., Bijlsma, L., Boehm, A.B., Brown, J., Buttiglieri, G., Calabro, V., Carducci, A., Castiglioni, S., Gurol, Z.C., Chakraborty, C., Costa, F., Curcio, S., de los reyes III, F.L., Delgado Vela, J., Farkas, K., Fernazdez-Casi, X., Gerba, C., Gerrity, D., Girones, R., Gonzzalez, R., Haramoto, E., Harris, A., Holden, P.A., Ispam, M.T., Jones, D.L., Kasprzyk-Hordern, B., Kitajima, M., Kotlarz, N., Kumar, M., Kuroda, K., La Rosa, G., Malpei, F., Mautus, M., Mclellan, S.L., Medema, G., Meschke, J.S., Mueller, J., Newton, R.J., Noble, R.T., van Nuijs, A., Peccia, J., Perkins, T.A., Pickering, A.J., Rose, J., Sanchez, G., Smith, A., Stadler, L., Stauber, C., Thomas, K., van der Voorn, T., Wiggington, K., Zhu, K., Bibby, K., 2020. Wastewater-based epidemiology: global collaborative to maximize contributions in the fight against COVID-19. Environ. Sci. Technol. 54(13), 7754-7757.

Blanchard, P., Guillot, S., Antùnez, K., Köglberger, H., Kryger, P., De Miranda, J.R., Francoa, S., Chauzat, M.P., Thiérya, R., Ribièrea, M., 2014. Development and validation of a realtime two-step RT-qPCR TaqMan ${ }^{\circledR}$ assay for quantitation of Sacbrood virus (SBV) and its application to a field survey of symptomatic honeybee colonies. J. Virol. Methods. 197, 713.

Bustin, S., Coward, A., Sadler, G., Teare, L., Nolan, T., 2020. CoV2-ID, a MIQE-compliant sub-20-min 5-plex RT-PCR assay targeting SARS-CoV-2 for the diagnosis of COVID-19. Sci. Rep. 10, 22214.

Bustin, S.A., Benes, V., Garson, J.A., Hellemans, J., Huggett, J.F., Kubista, M., Mueller, R.D., Nolan, T., Pfaffl, M.W., Shipley, G.L., Vandesompele, J., Wittwer, C.T., 2009. The MIQE guidelines: Minimum information for publication of quantitative real-time PCR experiments. Clin. Chem. 55, 611-622.

Cai, P., Huang, Q., Zhang, X., 2006. Interactions of DNA with clay minerals and soil colloidal particles and protection against degradation by DNase. Environ. Sci. Technol. 40, 29712976.

Calcott, P.H., 1978. Freezing and thawing microbes. Meadowfield Press, ISA Building.

Cao, Y., Griffith, J.F., Dorevitch, S., Weisberg, S.B., 2012. Effectiveness of qPCR permutations, internal controls and dilution as means for minimizing the impact of inhibition while measuring Enterococcus in environmental waters. J Appl Microbiol. 113 (1), 66-75.

Cao, Y., Raith, M.R., Griffith, J.F., 2015. Droplet digital PCR for simultaneous quantification of general and human-associated fecal indicators for water quality assessment. Water Res. 70, 337-349.

CDC., 2021. COVIDView. A weekly surveillance summary of U.S. COVID-19 Activity.

CDC., 2020. Coronavirus Disease 2019 (COVID-19). Centers for Disease Control and Prevention https://www.cdc.gov/coronavirus/2019-ncov/cases-updates/wastewatersurveillance/testing-methods.html.

CDC., 2020. https://www.cdc.gov/coronavirus/2019-ncov/downloads/COVID19symptoms.pdf. 
Centers for Disease Control and Prevention. 2020. CDC 2019-novel coronavirus (2019$\mathrm{nCoV}$ ) real-time RT-PCR diagnostic panel for emergency use only instructions for use. CDC, Atlanta.

Cervantes-Avilés, P., Moreno-Andrade, I., \& Carrillo-Reyes, J., 2021. Approaches applied to detect SARS-CoV-2 in wastewater and perspectives post-COVID-19. J. Water Process Eng. 40, 101947.

Cevik, M., Tate, M., Lloyd, O., Maraolo, A.E., Schafers, J., Ho, A., 2021. SARS-CoV-2, SARS-CoV, and MERS-CoV viral load dynamis, duration of viral shedding, and infectiousness: a systematic review and meta-analysis. Lancet Microb. 2, E13-E22.

Chavarria-Miro, G., Anfruns-Estrada E, Mrtinez-Valazquez, A., Vazquez-Portero M, Guix, S., Paraira, M., Galofre, B., Sanchez, G., Pinto, R.M., Bosch, A., 2021. Time-evolution of SARS-CoV-2 in wastewater during the first pandemic wave of COVID-19 in the metropolitan area of Barcelona. Appl. Environ. Microbiol. 10.1128/AEM.02750-20.

Chu, D.K.W., Pan, Y., Cheng, S.M.S., Hui, K.P.Y., Krishnan, P., Liu, Y., Ng, D.Y.M., Wan, C.K.C., Yang, P., Wang, Q., Peiris, M., Poon, L.L.M., 2020. Molecular diagnosis of a novel coronavirus (2019-nCoV) causing an outbreak of pneumonia. Clin. Chem. 66 (4), 549-555.

Ciesielski, M., Blackwood, D., Clerkin, T., Gonzalez R., Thompson, H., Larson, A., Noble, R., 2021. Assessing Sensitivity and Reproducibility of Two Molecular Workflows for the Detection of SARS-CoV-2 in Wastewater (under review).

Corman, V.M., Landt, O., Kaiser, M., Molencamp, R., Meijer, A., Chu, D.K.W., Bleicker, T., Brunink, S., Schneider, J., Schmidt, M.L., Mulders, D.G.J.C., Haagmans, B.L., van der Veer, B., van den Brink, S., Wijsman, L., Goderski, G., Romette, J.-L., Ellis, J., Zambon, M., Peiris, M., Goossens, H., Reusken, C., Koopman, M.P.G., Drosten, C., 2020. Detection of 2019 novel coronavirus (2019-nCoV) by real-time RT-PCR. Euro Surveill. 25 (3), 2000045.

D’Aoust, P.M., Mercier, E., Montpetit, D., Jia, J.-J., Alexandrov, I., Neault, N., Baig, A.T., mayne, J., Zhang, X., Alain, T., Langlois, M.-A., Servos, M.R., MacKenzie, M., Figeys, D., MacKenzie, A.E., Garber, T.E., Delatolla, R., 2020. Quantitative analysis of SARS-CoV-2 RNA from wastewater solids in communities with low COVID-19 incidence and prevalence. Water Res. 188, 116560.

Dong, E., Du, H., Gardner, L., 2020. An interactive web-based dashboard to track COVID-19 in real-time. Lancet Infect. Dis. 20 (5), 533-534.

Esbensen, K.H., Ramsey, C.A., 2015. QC of sampling processes - a first overview: from field to test portion. J. AOAC Int. 98, 282-287.

Espinosa, M.F., Sancho, A.N., Mendoza, L.M., Mota, C.R. and Verbyla, M.E., 2020. Systematic review and meta-analysis of time-temperature pathogen inactivation. Int. J. Hyg. Environ. Health, 230, 113595.

Falzone, L., Musso, N., Gattuso, G., Bongiorno, D., Palermo, C.I., Scalia, G., Libra, M., Stefani, S., 2020. Sensitivity assessment of droplet digital PCR for SARS-CoV-2 detection. Int. J. Mol. Med. 46, 957-964.

Forootan, A., Sjoback, R., Bjorkman, J., Sjogreen, B., Linz, L., Kubista, M., 2017. Methods to determine limit of detection and limit of quantification in quantitative real-time PCR (qPCR). Biomol. Detect. Quantif. 12, 1-6.

Fomsgaard, A.S., Rosenstierne, M.W., 2020. An alternative workflow for molecular detection of SARS-CoV-2 - escape from the NA extraction kit-shortage, Copenhagen, Denmark, March 2000. Euro Surveill. 25(14), 2000398.

Forés, E., Bofill-Mas, S., Itarte, M., Martínez-Puchol, S., Hundesa, A., Calvo, M., Borrego, C.M., Corominas, L.L., Girones, R., Rusiñol, M., 2021. Evaluation of two rapid ultrafiltration-based methods for SARS-CoV-2 concentration from wastewater. Sci. Total Environ. 768, 144786. 
Gandhi, M. Yokoe, D.S., Havlir, D.V., 2020. Asymptomatic transmission, the Achilles's heel of current strategies to control Covid-19. N. Engl. J. Med. 382, 2158-2160.

Gerrity, D., Papp, K., Stoker, M., Sims, A., Frehner, W., 2021. Early-pandemic wastewater surveillance of SARS-CoV-2 in Southern Nevada: Methodology, occurrence, and incidence/prevalence considerations. Water Res X. 10, 100086.

Gholipour, S., Nikaeen, M., Manesh, R.M., Aboutalebian, S., Shamsizadeh, Z., Nasri, E., Mirhendi, H., 2020. Severe acute respiratory syndrome coronavirus 2 (SARS-CoV-2) contamination of high-touch surfaces in field settings. Biomed. Environ. Sci. 33, 925-929.

Gibson, K.E., Schwab, K.J., Spencer, S.K., Borchardt, M.A., 2012. Measuring and mitigating inhibition during quantitative real time PCR analysis of viral nucleic acid extracts from large-volume environmental water samples. Water Res. 46(13), 4281-4291.

Giri, A.K., Rana, D.R., 2020. Charting the challenges behind the testing of COVID-19 in developing countries: Nepal as a case study. Biosaf. Heal. 2, 53-56.

Gonzalez, R., Curtis, K., Bivins, A., Bibby, K., Weir, M.H., Yetka, K., Thompson, H., Keeling, D., Mitchell, J., Gonzalez., 2020. COVID-19 surveillance in Southeastern Virginia using wastewater-based epidemiology. Water Res. 186, 116296.

Graham KE, Loeb SK, Wolfe MK, Catoe D, Sinnott-Armstrong N, Kim S, Yamahara KM, Sassoubre LM, Mendoza Grijalva LM, Roldan-Hernandez L, Langenfeld K, Wigginton KR, Boehm AB. 2021. SARS-CoV-2 RNA in wastewater settled solids is associated with COVID-19 cases in a large urban sewershed. Environ Sci. Technol. 55(1), 488-498.

Griffin, S.M., Brinkman, N.E., Hedrick, E.J., Rhodes, E.R., Fout, G.S., 2014. Comparison of nucleic acid extraction and reverse transcription-qPCR approaches for detection of GI and Gll noroviruses in drinking water. J. Virol. Methods. 199, 76-85.

Hamouda M, Mustafa F, Maraqa M, Rizvi T, Aly Hassan A. Wastewater surveillance for SARS-CoV-2: Lessons learnt from recent studies to define future applications. Sci Total Environ. 759, 143493.

Haramoto, E., Malla, B., Thakali, O., Kitajima M., 2020. First environmental surveillance for the presence of SARS-CoV-2 RNA in wastewater and river water in Japan. Sci. Total Environ. 737, 140405.

Harris-Lovett, S., Nelson, K., Beamer, P., Bischel, H.N., Bivins, A., Bruder, A., Butler, C., Camenisch, T.D., De Long, S.K., Karthikeyan, S., Larsen, D.A., Meierdiercks, K., Mouser, P., Pagsuyoin, S., Prasek, S., Radniecki, T.S., Ram, J.L., Roper, D.K., Safford, H., Sherchan, S.P., Shuster, W., Stalder, T., Wheeler, R.T., Korfmacher, K.S., 2020. Wastewater surveillance for SARS-CoV-2 on college campuses: initial efforts, lessons learned and research needs. MedRXiv. https://doi.org/10.1101/2021.02.01.21250952.

Hata, A., Katayama, H., Kitajima, M., Visvanathan, C., Nol, C., Furumai, H., 2011. Validation of internal controls for extraction and amplification of nucleic acids from enteric viruses in water samples. Appl. Environ. Microbiol. 77(13), 4336-4343.

Haugland, R.A., Siefring, S., Varma, M., Oshima, K.H., Sivaganesan, M., Cao, Y., Raith, M., Griffith, J., Weisberg, S.B., Noble, R.T., Blackwood, A.D., Kinzelman, J., Anan'eva, T., Bushon, R.N., Stelzer, E.A., Harwood, V.J., Gordon, K.V., Sinigalliano, C., Multilaboratory survey of qPCR enterococci analysis method performance in U.S. coastal and inland surface waters. 2016. J. Microbiol. Methods. 123, 114-125.

Hokajärvi, A.-M., Rytkönen, A., Tiwari, A., Kauppinen, A., Oikarinen, S., Lehto, K.-M., Kankaanpää, A., Gunnar, T., Al-Hello, H., Blomqvist, S., Miettinen, I.T., SavolainenKopra, C., Pitkänen, T., 2020. The detection and stability of the SARS-CoV-2 RNA biomarkers in wastewater influent in Helsinki, Finland. Sci. Total Environ. 770, 145274.

Huggett, J.F., Foy, C.A., Benes, V., Emslie, K., Garson, J.A., Haynes, R., Hellemans, J., Kubista, M., Mueller, R.D., Nolan, T., Pfaffl, M.W., Shipley, G.L., Vandesompele, J., Wittwer, C.T., Bustin, S.A., 2013. The digital MIQE Guidelines: Minimum Informantion for publication of quantitative digital PCR experiments. Clin. Chem. 59, 892-902. 
Huggett, J.F., Benes, V., Bustin, S.A., Garson, J.A., Harris, K., Kammel, M., Kubista, M., McHugh, T.D., Moran-Gilad, J., Nolan, T., Pfaffl, M.W., Salit, M., Shipley, G., Vallone, P.M., Vandesompele, J., Wittwer, C., Zeichhardtt, H., 2020. Cautionary note on contamination of reagents used for molecular detection of SARS-CoV-2. Clin. Chem. 66, 1369-1372.

Iker, B.C., Bright, K.R., Pepper, I.L., Gerba, C.P. and Kitajima, M. 2013. Evaluation of commercial kits for the extraction and purification of viral nucleic acids from environmental and fecal samples. J. Virol. Methods 191(1), 24-30.

ISO 15216-1:2017. Microbiology of the food chain - Horizontal method for determination of hepatitis A virus and norovirus using real-time RT-PCR - Part 1: Method for quantification.

Jafferali, M.H., Khatami, K., Atasoy, M., Birgersson, M., Williams, C., Cetecioglu, Z., 2020. Benchmarking virus concentration methods for quantification of SARS-CoV-2 in raw wastewater. Sci. Total Environ. 755, 142939.

Johnson, G., Nour, A.A., Nolan, T., Huggett, J., Bustin, S., 2014. Minimum information necessary for quantitative real-time PCR experiments. Methods Mol. Biol. 1160, 5-17.

Kim, D., Lee, J.-Y., Yang, J.-S., Kim, J.W., Kim, V.N., Chang, H., 2020. The architecture of SARS-CoV2 transcriptome. Cell. 181(4), 914-921.

Jones, D.L., Baluja, M.Q., Graham, D.W., Corbishley, A., McDonald, J.E., Malham, S.K., Hillary, L.S., Connor, T.R., Gaze, W.H., Moura, I.B., Wilcox, M.H., Farkas, K., 2020. Shedding of SARS-CoV-2 in feces and urine and potential role in person-to-person transmission and the environment-based spread of COVID-19. Sci. Total Environ. 749, 141364.

Kitajima, M., Ahmed, W., Bibby, K., Carducci, A., Gerba, C.P., Hamilton, K.A., Haramoto, E., Rose, J.B., 2020. SARS-CoV-2 in wastewater: State of the knowledge and research needs. Sci. Total Environ. 739, 139076.

Korajkic, A., Wanjugi, P., Brooks, L., Cao, Y., Harwood, V.J., 2019. Persistence and decay of fecal microbiota in aquatic habitats. Microbiol. Mol. Biol. Rev. 83(4), e00005-19.

Koponen, J.K., Turunen, A.M., Ylä-herttuala, S., 2002. Escherichia coli DNA contamination in AmpliTq Gold polymerase interferes with TaqMan analysis of lacZ. Mol. Ther. 5 (3), 220-222.

La Rosa, G., laconelli, M., Mancini, P., Bonanno, G., Ferraro, G.B., Veneri, C., Bonadonna, L., Lucentini, L., Suffredini, E., 2020. First detection of SARS-CoV-2 in untreated wastewaters in Italy. Sci. Total Environ. 736, 139652.

La Rosa G, Mancini P, Bonanno Ferraro G, Veneri C, laconelli M, Bonadonna L, Lucentini L, Suffredini E. 2021. SARS-CoV-2 has been circulating in northern Italy since December 2019: Evidence from environmental monitoring. Sci. Total. Environ. 750, 141711.

Layton, B.A., Cao, Y., Ebentier, D.L., Hanley, K., Balleste, E., Brandao, J., Byappanahalli, M., Converse, R., Farnleitner, A.H., Gentry-Shields, J., Gidley, M.L., Gourmelon, M., Lee, C.S., Lee, J., Lozach, S., Madi, T., Meijer, W.G., Noble, R., Peed, L., Reischer, G.H., Rodrigues, R., Rose, J.B., Schriewer, A., Sinigalliano, C., Srinivasan, S., Stewart, J., Van De Werfhorst, L.C., Wang, D., Whitman, R., Wuertz, S., Jay, J., Holden, P.A., Boehm, A.B., Shanks, O., Griffith, J.F., 2013.Performance of human fecal anaerobe-associated PCR-based assays in a multi-laboratory method evaluation study. Water Res. 47(18), 6897-6908.

Li, N., Wang, P., Wang, X., Geng, C., Chen, J., Gong, Y., 2020. Molecular diagnosos of COVID-19: current situation and trend in China. Exp. Ther. Med. 20 (5), 13.

Li, D., Zhang, J., Li, J., 2020. Primer design for quantitative real-time PCR for the emerging coronavirus SARS-CoV-2. Theranostics. 10 (16), 7150-7162.

Li, X., Giorgi, E.E., Marichannegowda, H.M., Foley, B., Xiao, C., Kong, X.-P., Chen, Y., Gnakaran, S., Korber, B., Gao, F., 2020. Emergence of SARS-CoV-2 through recombination and strong purifying selection. Sci. Adv. 6(27), eabb9153.

Liu, C., Shi, Q., Peng, M., Lu, R., Li, H., Cai, Y., Chen, J., Xu, J., Shen, B., 2020. Evaluation of droplet digital PCR for quantification of SARS-CoV-2 virus in discharged COVID-19 patients. Aging (Albany NY). 12 (21), 20997-21003.

Liu, Y.N., Lv, Z.T., Yang, S.Y., Liu, X.W., 2021. Optical tracking of the interfacial dynamics of single SARS-CoV-2 pseudoviruses. Environ. Sci. Technol. doi:10.1021/acs.est.0c06962.

Lodder, W., de Roda Husman, A.M., 2020. SARS-CoV-2 in wastewater: potential health risk, but also data source. Lancet Gastroenterol. Hepatol. 5 (6), 533-534.

Lund, E., Hedström C.-E., 1969. A study on sampling and isolation methods for the detection of virus in sewage. Water Res. 3 (11), 823-832. 
Lv, J., Yang, J., Xue, J., Zhu, P., Liu, L., Li, S., 2020. Detection of SARS-CoV-2 RNA residue on object surfaces in nucleic acid testing laboratory using droplet digital PCR. Sci. Total Environ. 742, 1-6.

Mascuch, S.J., Fakhretaha-Aval, S., Bowman, J.C., Ma, M.T.H., Thomas, G., Bommarius, B., Ito, C., Zhao, L., Newnam, G.P., Matange, K.R., Thapa, H.R., Barlow, B., Donegan, R.K., Nguyen, N.A., Saccuzzo, E.G., Obianyor, C.T., Karunakaran, S.C., Pollet, P., Rothschild-Mancinelli, B., MestreFos, S., Guth-Metzler, R., Bryksin, A.V., Petrov, A.S., Hazell, M., Ibberson, C.B., Penev, P.I., Mannino, R.G., Lam, W.A., Garcia, A.J., Kubanek, J.M., Agarwal, V., Hud, N.V., Glass, J.B., Williams, L.D., Lieberman, R.L., 2020. Buzz about RT-qPCR: An RT-qPCR formulation for SARSCoV-2 detection using reagents produced at Georgia Institute of Technology. medRxiv. doi:10.1101/2020.07.29.20163949.

Matrajt, G., Naughton, B., Bandyopadhyay, A.S., Meschke, J.S., 2018. A review of the most commonly used methods for sample collection in environmental surveillance of poliovirus. Clin. Infect. Dis. 67, S90-S97.

McEvoy B, Rowan, M.J., 2019. Terminal sterilization of medical devices using vaporized hydrogen peroxide: a review of current methods and emerging opportunities. J. Appl. Microbiol. 127(5), 14031420.

McMinn, B., Korajkic, A., Kelleher, J., Herrmann, M.P., Pemberton, A.C., Ahmed, W., Villegas, E.N., Oshima, K., 2021. Development of a Large Volume Concentration Method for Recovery of Coronavirus from Wastewater. Sci. Total Environ (accepted).

Medema, G., Heijnen, L., Elsinga, G., Italiaander, R., 2020a. Presence of SARS-Coronavirus-2 RNA in sewage and correlation with reported COVID-19 prevalence in the early stage of the epidemic in the Netherlands. Environ. Sci. Technol. Lett. 7 (7), 511-516.

Medema, G., Been, F., Heijnen, L., Petterson, S., 2020b. Implementation of environmental surveillance for SARS-CoV-2 virus to support public health decisions: opportunities and challenges. Curr. Opin. Environ. Sci. Health. 17, 49-71.

Merindol, N., Pepin, G., Marchand, C., Rheault, M., Peterson, C., Porier, A., Houle, C., Germain, H., Danylo, A., 2020. SARS-CoV-2 detection by direct rRT-PCR without RNA extraction. J. Clin. Virol. 128, 104423.

Millar, B.C., Xu, J., Moore, J.E., 2002. Risk assessment models and contamination management: implications for broad-range ribosomal DNA PCR as a diagnostic tool in medical bacteriology. J. Clin. Microbiol. 40, 1575-1580.

Michael-Kordatou, I., Karaolia, P., Fatta-Kassinos, D., 2020. Sewage analysis as a tool for the COVID19 pandemic response and management: the urgent need for optimised protocols for SARS-CoV-2 detection and quantification. J. Environ. Chem. Eng. 8(5), 104306.

Miyani, B., Fonoll, X., Norton, J., Mehrotra, A., Xagoraraki, I., 2020. SARS-CoV-2 in Detroit wastewater. J Environ. Eng. 146(11).

Mögling, R., Meijer, A., Berginc, N., Bruisten, S., Charrel, R., Coutard, B., Eckerle, I., Enouf V., Hungnes, O., Korukluoglu G., Kossyvakis, T., Mentis, A., Molenkamp, R., Muradrasoli, S., Papa, A., Pigny, F., Thirion, L., Van Der Werf, S., Reusken, C., 2020. Delayed laboratory responses to COVID-19 caused by molecular diagnostic contamination. Emerg. Infect. Dis. 26, 1944-1946.

Muirhead, A., Zhu, K., Brown, J., Basu, M., Brinton, M.A., Costa, F., Hayat, M.J., Satauber, C.E., 2020. Zika virus persistence in sewage. Environ. Sci. Technol. Lett. (online early).

Murray, T.Y., Mans, J., van Zyl, W.B., Taylor, M.B., 2013. Application of a competitive internal amplification control for the detection of sapoviruses in wastewater. Food Environ. Virol. 5(1), 61-8.

Naughton, C.C., Roman Jr., F.A., Alvarado, A.G.F., Tariqi, A.Q., Deeming, M.A., Bibby, K., Bivins, A., Rose, J.B., Medema, G., Ahmed, W., Katsivelis, P., Allan, V., Sinclair, R., Zhang, Y., Kinyua, M.N., 2021. Show us the data: Global COVID-19 wastewater monitoring efforts, equity, and gaps. MedRXiv. doi: https://doi.org/10.1101/2021.03.14.21253564.

Nishiura, H., Kobayashi, T., Miyama, T., Suzuki, A., Jung, S-K., Hayashi, K., Kinoshita, R., Yang, Y., Yuan, B., Akhmetzhanov, A.R., Linton, N.M., 2020. Estimation of the asymptomatic ratio of novel coronavirus infections (COVID-19). Int. J. Infect. Dis. 94, 154-155.

Oran, D.P., Topol, E.J., 2020. Prevalence of asymptomatic SARS-CoV-2 infection: A narrative review. Ann. Intern. Med. M20-3012.

Ort, C., Lawrence, M.G., Reungoat, J. and Mueller, J.F. (2010a) Sampling for PPCPs in wastewater systems: Comparison of different sampling modes and optimization strategies. Environ. Sci. Technol. 44 (16), 6289-6296. 
Ort, C., Lawrence, M.G., Rieckermann, J. and Joss, A. (2010b) Sampling for pharmaceuticals and personal care products (PPCPs) and illicit drugs in wastewater systems: Are your conclusions valid? A critical review. Environ. Sci. Technol. 44(16), 6024-6035.

Park, C., Lee, J., Hassan, Z.U., Ku, K.B., Kim, S.J., Kim, H.G., Park E.C., Park, G.S., Park, D., Baeh, S.H., Park, D., Lee, J., Jeon, S., Kim, S., Lee, S., Yoo, H.M., Kim, S.J., 2020. Comparison of digital PCR and quantitative PCR with various SARS-CoV-2 primer-probe sets. Microbiol. Biotechnol. 10.4014/jmb.2009.09006.

Pecson, B.M., Darby, E., Haas, C.N., Amha, Y.M., Bartolo, M., Danielson, R., Dearborn, Y., Giovanni, G.D., Ferguson, C., Fevig, S., Gaddis, E., Gray, D., Lukasik, G., Mull, B., Olivas, L., Olivieri, A., Qu, Y., 2021. Reproducibility and sensitivity of 36 methods to quantify the SARS-CoV-2 genetic signal in raw wastewater: findings from an interlaboratory methods evaluation in the US. Environ. Sci.: Water Res. Technol. Advance article.

Peccia, J., Zulli, A., Brackney, D.E. Grubaugh, N.D., Kaplan, E.H., Casanovas-Massana, A., Ko, A.I., Malik, A.A., Wang, D., Warren, J.L., Weinberger, D.N., Arnold, W., Omer, S.B., 2020. Measurement of SARS-CoV-2 RNA in wastewater tracks community infection dynamics. Nat.

Biotechnol. 38:1164-1167. Peñarrubia, L., Ruiz, M., Porco, R., Rao, S.N., Juanola-Falgarona, M., Manissero, D., López-Fontanals, M., Pareja, J., 2020. Multiple assays in a real-time RT-PCR SARS-CoV-2 panel can mitigate the risk of loss of sensitivity by new genomic variants during the COVID-19 outbreak. Int. J. Infect. Dis. 97, 225-229.

Perez-Cataluna, A., Cuevas-Ferrando, E., Randazzo, W., Falco-AnaAllende, I., Sanchez, G., Comparing analytical methods to detect SARS-CoV-2 in wastewater. Sci. Total Environ. 758, 143870.

Philo, S.E., Keim, E.K., Swanstrom, R., Ong, A.Q.W., Burnor, E.A., Kossik, A.L., Harrison, J.C., Demeke, B.A., Zhou, N.A., Beck, N.K., Shirai, J.H., Meschke, J.S., 2021. A comparison of SARSCoV-2 wastewater concentration methods for environmental surveillance. Sci. Total Environ. 760, 144215.

Prado, T., Fumian, T.M., Mannrino, C.F., Maranhao, A.G., Siqueira, M.M., Miagostovich, M.P., 2020. Preliminary results of SARS-CoV-2 detection in sewerage system in Niteroi municipality, Rio de Janeiro, Brazil. Mem. Inst. Oswaldo Cruz. 115, e200196.

Randazzo, W., Truchado, P., Ferranfo, E.C., Simon, P., Allende, A., Sanchez, G., 2020. SARS-CoV-2 RNA titers in wastewater anticipated COVID-19 occurrence in a low prevalence area. Water Res. 115942.

Rimoldi, S.G., Stefani, F., Gigantiello, A., Polesello, S., Comandatore, F., Mileto, D., Maresca, M., Longobardi, C., Mancon, A., Romeri, F., Pagani, C., Cappelli, F., Roscioli, C., Moja, L., Gismondo, M.R., Salerno, F., 2020. Prevalence and infectivity of SARS-CoV-2 virus in wastewaters and rivers. Sci. Total Environ. 744, 140911.

Rosario K, Symonds E.M., Sinigalliano, C., Stewart, J., Breitbart, M., 2009. Pepper mild mottle virus as an indicator of fecal pollution. Appl. Environ. Microbiol. 75(22), 7261-7267.

Rusiñol, M., Martínez-Puchol, S., Forés, E., Itarte, M., Girones, R., Bofill-Mas, S., 2020. Concentration methods for the quantification of coronavirus and other potentially pandemic enveloped virus from wastewater. Curr. Opin. Environ. Sci. Health. 17, 21-28.

Saawarn, B., Hait, S., 2021. Occurrence, fate and removal of SARS-CoV-2 in wastewater: current knowledge and future perspectives. J. Environ. Chem. Eng. 9 (1), 104870.

Salehi, Z., Najafi, M., 2014. RNA preservation and stabilization. Biochem Physiol. 3(126), 2.

Schrader, C., Schielke, A., Ellerbroek, L., Johne, R., 2012. PCR inhibitors - occurrence, properties and removal. J Appl Microbiol. 113(5), 1014-1026.

Schang, C., Crosbie, N.D., Nolan, M., Poon, R., Wang, M., Jex, A., Scales, P., Schmidt, J., Thorley, B.R., Henry, R., Kolotelo, P., Langeveld, J., Schilperoot, R., Shi, B., Einsiedel, S., Thomas, M., Black,I J., Wilson, S., McCarthy, D.T., 2021. Passive sampling of viruses for wastewater-based epidemiology: a case-study of SARS-CoV-2.

Shanks, O.C., Kelty, C.A., Oshiro, R., Haugland R.A., Madi, T., Brooks, L., Field, K.G., Sivaganesan M. 2016. Data acceptance criteria for standardized human-associated fecal source identification quantitative real-time PCR methods. Appl. Environ. Microbiol. 82, 2773-2782.

Stachler, E., Kelty, C., Sivaganesan, M., Li, X., Bibby, K., Shanks, O.C., 2017. Quantitative crAssphage PCR assays for human fecal pollution measurement. Environ. Sci. Technol. 51(16), 9146-9154.

Stadler, L.B., Ensor, K., Clark, J.R., Kalvapalle, P., LaTurner, Z.W., Mojica, L., Terwilliger, A.L., Zhuo, Y., Ali, P., Avadhanula, V. and Bertolusso, R., 2020. Wastewater Analysis of SARS-CoV-2 as a 
Predictive Metric of Positivity Rate for a Major Metropolis. medRxiv. https://doi.org/10.1101/2020.11.04.20226191.

Steele, J., Zimmer-Faust A., Griffith, J.F., 2021. Sources of variability in methods for processing, storing, and concentrating SARS-CoV-2 in influent from urban wastewater treatment plants (under review).

Suo T., Liu X., Feng J., Guo M., Hu W., Guo D., Ullah H., Yang Y., Zhang Q., Wang X. 2020. ddPCR: a more accurate tool for SARS-CoV-2 detection in low viral load specimens. Emerg. Microb. Infect. 9, 1259-1268.

Tan, S.K., Sahoo, M.K., Milligan, S.B., Taylor, N., Pinksy, B.A., 2017. Stability of Zika virus in urine: specimen processing considerations and implications for the detection of RNA targets in urine. J. Virol. Met. 248, 66-70.

Tahamtan, A., Ardebili, A., 2020. Real-time RT-PCR in COVID-19 detection: issues affecting the results. Expert Rev. Mol. Diagn. 20, 453-454.

Taylor, S.C., Nadeau, K., Abbasi, M., Nguyen, M., Fenrish, J., 2019. The ultimate qPCR experiment: producing publication quality, reproducible data the first time. Trends Biotechnol. 37(7), 761-774.

Tedim, A.P., Almansa, R., Dominguez-Gil, M., Gonzalez-Rivera, M., Micheloud, D., Ryan, P., Mendez, R., Blanca-Lopez, N., Perez-Garcia, F., Bustamante, E., Gomez, J.M., Doncel, C., Trapiello, W., Kelvin, A.A., Booth, R., Ostadgavahi, A.T., Oneizat, R., Puertas, C., Barbe, F., Ferrer, R., Menendez, R., Bermejo-Martin, J.F., Eiros, J.M., Kelvin, D.J., Torres, A., 2021. Comparison of real time and droplet digital PCR to detect and quantify SARS-CoV-2 RNA in plasma. Eur. J. Clin. Invest. E13501. doi: 10.1111/eci.13501.

Thompson, J.R., Nancharaiah, Y.V., Gu X., Lee, W.L., Rajal V.B., Haines M.B., Girones, R., Ng L.C., Alm E.J., Wuertz, S., 2020. Making waves: Wastewater surveillance of SARS-CoV-2 for populationbased health management. Water Res. 184, 116181.

Torii, S., Furumai, H., Katayama, H., 2020. Applicability of polyethylene glycol precipitation followed by acid guanidinum thiocyanate phenol-chloroform extraction for the detection of SARS-CoV-2 RNA from municipal wastewater. Sci. Total Environ. 756, 143067.

Teerlink, J., Hering, A.S., Higgins, C.P., Drewes, J.E. (2012) Variability of trace organic chemical concentrations in raw wastewater at three distinct sewershed scales. Water Research 46(10), 32613271.

The dMIQE Group, Huggett J.F., The digital MIQE guidelines undate: Minimum information for publication of quantitative digital PCR experiments for 2020. Clin. Chem. 66(8), 1012-1029.

US EPA, 2014. Sampler's Guide: Contract laboratory program guidance for field samplers. EPA-540-R014-013. OSWER 9200.2-147.

Vogels, C.B.F., Brito, A.F., Wyllie, A.L., Fauver, J.R., Ott, I.M., Kalinich, C.C., Petrone, M.E., Casanovas-Massana, A., Catherine Muenker, M., Moore, A.J., Klein, J., Lu, P., Lu-Culligan, A., Jiang, X., Kim, D.J., Kudo, E., Mao, T., Moriyama, M., Oh, J.E., Park, A., Silva, J., Song. E., Takhashi, Taura, M., Tokuyama, M., Venkataraman, A., Weizman, O-E., Wong, P., Yang, Y., Cheemarla, N.R., White, E.B., Lapidus, S., Earnest, R., Geng, B., Vijaykumar, P., Odio, C., Fournier, J., Bermejo, S., Farhadian, S., Dela Cruz, C.S., Iwasaki, A., Ko, A.I., Landry, M.L., Foxman, E.F., Grubaugh, N.D., 2020. Analytical sensitivity and efficiency comparisons of SARSCoV-2 RT-qPCR primer-probe sets. Nat. Microbiol. 5, 1299-1305.

Ward, S., Lindsley, A., Courter, J., Assa'ad A., 2020. Clinical testing for COVID-19. J. Allerg. Clin. Immunol. 146, 23-24.

Weidhaas, J., Aanderud, Z., Roper, D., VanDerslice, J., Gaddis, E., Ostermiller, J., Hoffman K., Jamal R., Heck P., Zhang Y., 2020. Correlation of SARS-CoV-2 RNA in wastewater with COVID-19 disease burden in sewersheds.

Westhaus, S., Weber, F.A., Schiwy, S., Linnemann, V., Brinkmann, M., Widera, M., Greve, C., Janke, A., Hollert, H., Wintgens, T., Ciesek, S., 2020. Detection of SARS-CoV-2 in raw and treated wastewater in Germany - Suitability for COVID-19 surveillance and potential transmission risks. Sci. Total Environ. 751, 141750.

Whitney, O.N., Kennedy, L.C., Fan, V., Hinkle, A., Kantor, R., Greenwald, H., Crits-Christoph, A., AlShayeb, B., Chaplin, M., Tijan, R., Nelson, K.R., 2020. Sewage, salt, silica and SARS-CoV-2 (4S): An economical kit-free method for direct capture of SARS-CoV-2 RNA from wastewater. medRxiv. doi: $10.1101 / 2020.12 .01 .20242131$.

WHO World Health Organization (WHO) list of in-house-developed molecular assays for SARS-CoV-2 detection. 2020. https://www.who.int/docs/default-source/coronaviruse/whoinhouseassays.pdf.

WHO., 2003. Guidelines for environmental surveillance of poliovirus circulation. Geneva. 
Wölfel, R., Corman, V.M., Guggemos, W., Seilmaier, M., Zange, S., Müller, M.A., Niemeyer, D., Jones, T.C., Vollmar, P., Rothe, C., Hoelscher, M., Bleicker, T., Brünink, S., Schneider, J., Ehmann, R., Zwirglmaier, K., Drosten, C., Wendtner, C., 2020. Virological assessment of hospitalized patients with COVID-2019. Nature. 581, 465-469.

Wang, X.-W., Li, J.-S., Guo, R.-K., Zhen, B., Kong, W.-X., Yi, B., Li, Z., Song, N., Jin, M., Xiao, W.-J., Zhu, X.-M., Giu, C.-Q., Yin, J., Wei, W., Yao, W., Liu, C., Li, J.-F., Ou, G.-R., Wang, M.-N., Fang, T.Y., Wang, G.-J., Qiu, Y.,-H., Wu, H.-H., Chao, F.-H., Li, J.-W., 2005. Concentration and detection of SARS coronavirus in sewage from Xiao Tang Shan Hospital and the $309^{\text {th }}$ Hospital. J. Virol. Methods. 128 (1-2), 156-161.

Wee, S.K., Sivalingam, S.P., Yap, E.P.H., 2020. Rapid direct nucleic acid amplification test without RNA extraction for SARS-CoV-2 using a portable PCR thermocycler. Genes. 11 (6), 664.

Wilson, C.C., Wozney, K.M., Smith, C.M., 2016. Recognizing false positives: synthetic oligonucleotide controls for environmental DNA surveillance. Methods Ecol. Evol. 7, 23-29.

Wu, F., Zhang, Z., Xiao, A., Gu, X., Lee, W.L., Armas, F., Kauffman, K., Hanage, W., Matus, M., Ghaeli, N., Endo, N., Duvallet, C., Poyet, M., Moniz, K., Washburne, A.D., Ericson, T.B., Chai, P.R., Thomson, J., Alm, E.J., 2020. SARS-CoV-2 titers in wastewater are higher than expected from clinical confirmed cases. mSystems. 5(4), e00614-20.

Wu, F., Xiao, A., Zhang, J., Moniz, K., Endo, N., Armas, F., Bushman, M., Chai, P.R., Duvallet, C., Ericson, T.B., Foppe, K., Ghaeli, N., Gu, X., Hanage, W.P., Huang, K.H., Lee, W.L., Matus, M., McElory, K.A., Rhode, S.F., Wuertz, S., Thompson, J., Alm, E.J., 2021. Wastewater surveillance of SARS-CoV-2 across 40 U.S. States.

Wurtzer, S., Waldman, P., Ferrier-Rembert, A., Frenois-Veyrat, G., Mouchel, J.M., Boni, M., Maday, Y., OBEPINE consortium, Marechal, V., Moulin, L., 2021. Several forms of SARS-CoV-2 RNA can be detected in wastewaters: implication for wastewater-based epidemiology and risk assessment. doi: https://doi.org/10.1101/2020.12.19.20248508.

Xu, Y., Li, X., Zhu, B., Liang, H., Fang, C., Gong, Y., Guo, Q., Sun, X., Zhao, D., Shen, J., Zhang, H., Liu, H., Xia, H., Tang, J., Zhang, K., Gong, S., 2020. Characteristics of pediatric SARS-CoV-2 infection and potential evidence for persistent fecal viral shedding. Nat. Med. 26, 502-505.

Ye, Y., Ellenberg, R.M., Graham, K.E., Wigginton, K.R., 2016. Survivability, partitioning, and recovery of enveloped viruses in untreated municipal wastewater. Environ. Sci. Technol. 50(10), 5077-85.

Yuan, C., wang, H., Li, K., Tang, A., Dai, Y., Wu, B., Zhang, H., Chen, J., Liu, J., Wu, W., Gu, S., Wang, H, Xu, H., Wu, M., Yu, M., Wang, Y., Yu, X., He, J., Liu, S., Zhang, Y., Tong, Z., Yan, J., 2021. SARS-CoV-2 viral shedding characteristics and potential evidence for the priority for faecal specimen testing in diagnosis. PLoS One. 16(2), e0247367.

Zhang, D., Lou, X., Yan, H., Pan, J., Mao, H., Tang, H., Shu, Y., Zhao, Y., Liu, L., Li, J., Chen, J., Zhang, Y., Ma, X., 2018. Metagenomic analysis of viral nucleic acid extraction methods in respiratory clinical samples. BMC Genomics. 19, 773.

Zhang, J.C., Wang, S.B., Xue, Y.D., 2020. Fecal specimen diagnosis 2019 novel coronavirus-infected pneumonia. J. Med. Virol (online early).

Ziegler, K., Steininger, P., Ziegler, R., Steinmann, J., Korn, K., Ensser, A., 2020. SARS-CoV-2 samples may escape detection because of a single point mutation in the $\mathrm{N}$ gene. Euro Surveill. 25(39), 2001650. 
